\title{
Biofilm formation mechanisms and targets for developing antibiofilm agents
}

\begin{abstract}
Biofilms are communities of microorganisms that are attached to a surface and play a significant role in the persistence of bacterial infections. Bacteria within a biofilm are several orders of magnitude more resistant to antibiotics, compared with planktonic bacteria. Thus far, no drugs are in clinical use that specifically target bacterial biofilms. This is probably because until recently the molecular details of biofilm formation were poorly understood. Bacteria integrate information from the environment, such as quorumsensing autoinducers and nutrients, into appropriate biofilm-related gene expression, and the identity of the key players, such as cyclic dinucleotide second messengers and regulatory RNAs are beginning to be uncovered. Herein, we highlight the current understanding of the processes that lead to biofilm formation in many bacteria.
\end{abstract}

Dating back to the seminal works of Robert Koch, the father of modern microbiology, to the 1970s, bacteria were largely considered as single free-floating microorganisms. Using the planktonic pure bacterial culture model, scientists have been able to study many deadly bacteria and developed biocides to kill such bacteria. The emergence of drug-resistant bacteria and the difficulty in killing some bacteria led to a re-evaluation of the bacterial lifestyle and it is now acknowledged that the aggregation of bacteria within self-produced matrices, called biofilms, endows bacteria with mechanisms to resist biocides. Biofilms were observed a few centuries before their relevance to the persistence of disease was realized. In 1684, a Dutch scientist, Antonie van Leeuwenhoek, saw dental plaque using his self-constructed microscope and he described it as scurf. During the early part of the 20th century many scientists reported that most bacteria were not free-floating but were attached to surfaces, such as the bottom of lakes [1,2]. Scientists began to realize that some sessile bacteria were directly related to disease when in 1977 Pseudomonas aeruginosa aggregation was found in sputum from the lungs of infected cystic fibrosis patients [3]. In 1978, Clark reported that an important component of Streptococcus mutans biofilm, polysaccharide glycocalyx formed on teeth. The term 'biofilm' was formally introduced in 1978 by Costerton [4]. Biofilms have varied morphologies, depending on the constituent bacteria as well as the conditions under which that biofilm was formed. See Figure 1 for a few examples of bacterial biofilms.

In the last few years, interests in biofilm formation by a group of clinically relevant bacteria, which cause high mortality, called ESKAPE (Enterococcus faecalis, Staphylococcus aureus, Klebsiella pneumoniae, Acinetobacter baumannii, $P$. aeruginosa and Enterobacter spp.) have intensified. There is an interest in understanding biofilm formation by bacteria that cause dental caries, such as Streptococcus sobrinus and $S$. mutans, and also there are many efforts to delineate biofilm mechanisms of bacteria that foul implants, such as Proteus mirabilis. In the sections that follow, we highlight current understanding in how the aforementioned and other bacteria form biofilms and targets or processes, for which small molecules can be developed against to inhibit bacterial biofilm formation.

\section{Biofilm structure}

The structure of the extracellular polymeric substance (EPS) matrix of bio-
Nira Rabin', Yue Zheng', Clement Opoku-Temeng', Yixuan Du', Eric Bonsu \& Herman O Sintim ${ }^{*, 1}$ 'Department of Chemistry \& Biochemistry, University of Maryland, College Park, MD 20742, USA 2Department of Natural Sciences, Bowie State University, 14000 Jericho Park Road, Bowie, MD 20715, USA *Author for correspondence: Tel.: +1 3014050633 Fax: +1 3013149121 hsintim@umd.edu 


\section{Key terms}

Extracellular polymeric substances: The biofilm is supported by a matrix of polymeric compounds. These compounds are secreted by bacteria into the environment. EPS are usually composed of exopolysaccharides, proteins and nucleic acids.

Exopolysaccharides: Exopolysaccharides are highmolecular-weight polymers that are composed of sugar residues and are secreted by bacteria into the surrounding environment.

films is composed of one or more of extracellular polysaccharides, DNA and proteins (Figure 2) [11]. Channels in the biofilm allow for water, air and nutrients to get to all parts of the structure [12].

\section{Exopolysaccharides}

Exopolysaccharides are either synthesized extracellularly or intracellularly and secreted into the outside environment [13]. In electron microscopy, they look like linear or branched long strands that are attached to cell surfaces and stretched out to form large networks (Figure 3). Exopolysaccharides serve as scaffolds for other carbohydrates, proteins, nucleic acids and lipids to adhere. The components, structures and properties of the exopolysaccharides differ from one another.

Nelson and coworkers analyzed the compositions and linkages of EPS matrix from E. faecalis, S. aureus, $K$. pneumoniae, A. baumannii, $P$. aeruginosa and E. spp. biofilms [15]. Mannose, galactose and glucose are the most abundant carbohydrates, followed by $N$-acetyl-glucosamine, galacturonic acid, arabinose, fucose, rhamnose and xylose. Most exopolysaccharides are not biofilm specific, but their production increases as a result of a stress response, such as colanic acid production in Escherichia coli [16] and alginate synthesis in P. aeruginosa [17]. Colanic acid (also known as M antigen) is an extracellular heteropolysaccharide found in
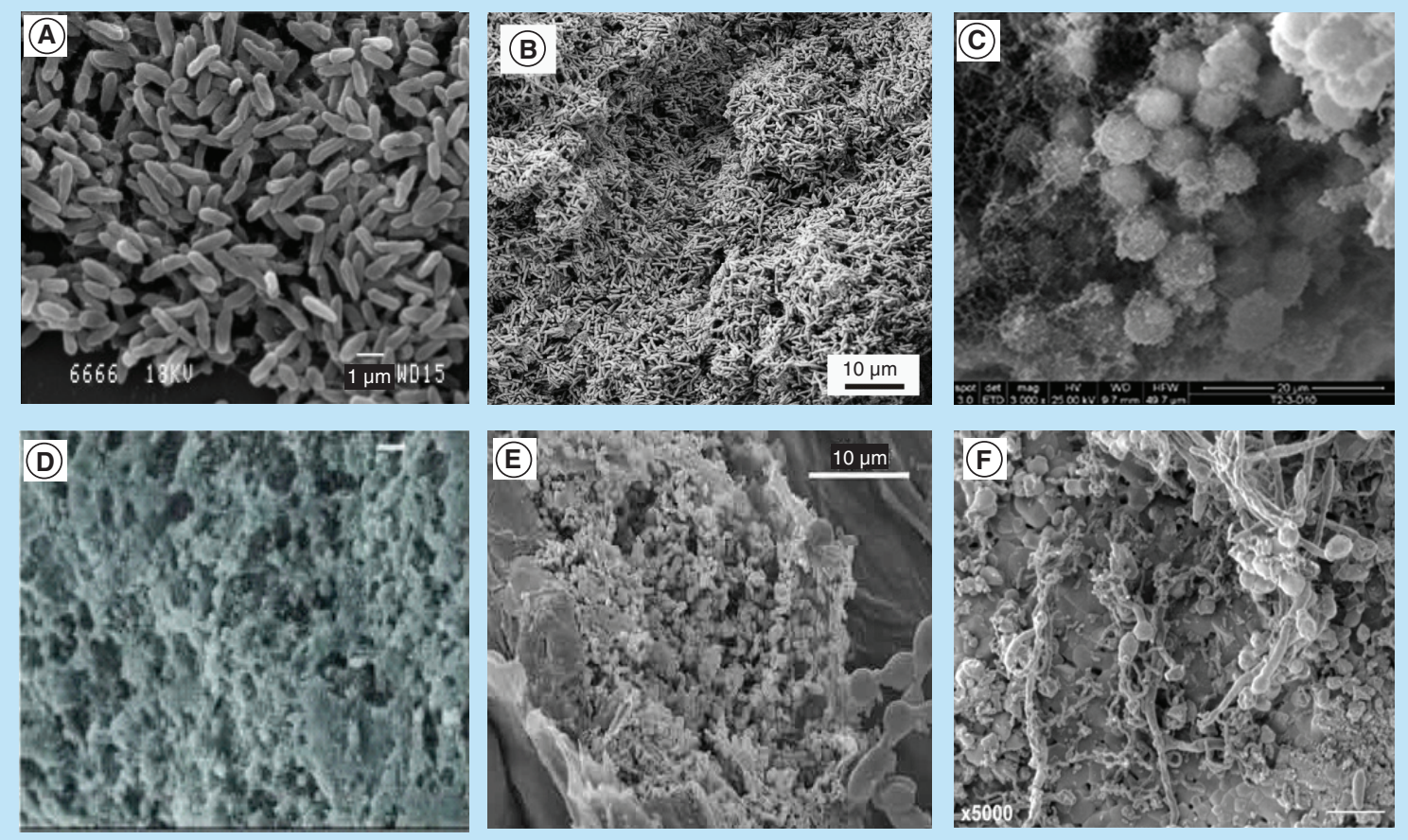

Figure 1. Bacterial biofilms. (A) SEM image of Pseudomonas aeruginosa isolates attaching to glass surfaces; (B) biofilm formation of Escherichia coli on titanium oxide surface; (C) SEM image of catheter-associated Staphylococcus aureus biofilm growth in vivo; (D) electron microscopy of Staphylococcus epidermidis biofilm formation on Teflon catheter; (E) SEM image showing attachment and biofilm formation by Salmonella enterica serovar Poona cells inside the netting of inoculated cantaloupe; (F) SEM of mature mixed biofilms formed on discs of hydroxyapatite, demonstrating the affinity of Streptococcus mutans to the hyphal elements of Candida albicans. SEM: Scanning electron microscopy.

(A) Reproduced from [5].

(B) Reproduced from [6].

(C) Reproduced with permission from [7] @ The Americanl Association of Immunologists, Inc. (2011).

(D) Rreproduced with permission from [8] @) Nature Publishing Group (2011).

(E) Rreproduced with permission from [9] ๔ John Wiley \& Sons (2008).

(F) Reproduced from [10]. 


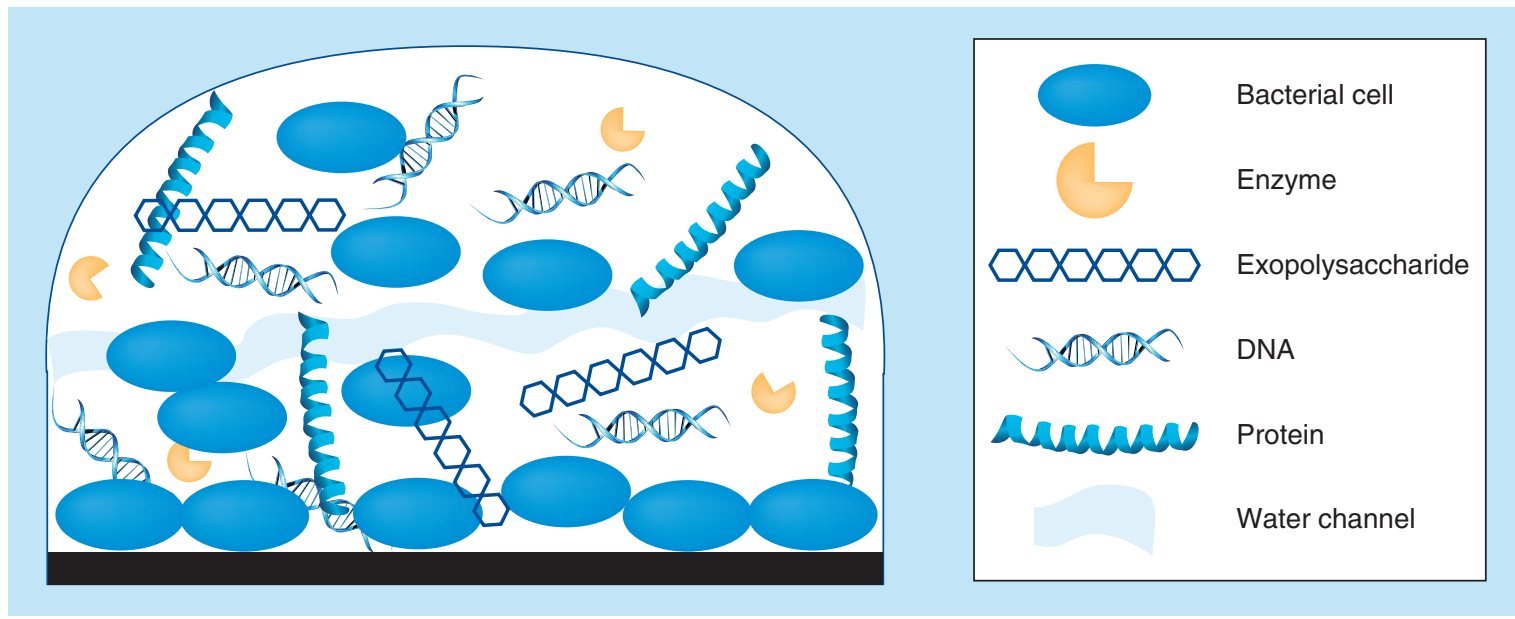

Figure 2. Biofilm structure.

Enterobacteriaceae [18]. The colanic acid repeat unit is made up of L-fucose, D-galactose, D-glucuronate and D-glucose and decorated with $O$-acetyl and pyruvate side chains [19]. The repeat units are assembled by glycosyl transferases on the cytoplasmic side of the inner cell membrane. Then the repeat units are flipped from the cytoplasm into the periplasm by Wzx. Wzy system is responsible for initial polymerization and highlevel polymerization is conducted by Wzc and Wzb. The outer-membrane protein Wza transports colanic acid polymers into the extracellular space [20]. E. coli $\mathrm{K}-12$ strain defective in colanic acid production has a slower initial attachment rate, but the attachment is not completely abolished [21].

There are three exopolysaccharides associated with $P$. aeruginosa biofilms: Pel [22], Psl [23,24] and alginate (Figure 4) [25]. Alginate is composed of D-mannuronic acid residues interspersed with L-guluronic acid residues (Figure 5B). Alginate is not involved in biofilm initiation, but it is a critical virulence factor in chronic infections. Alginate protects $P$. aeruginosa cells from antibiotics such as ciprofloxacin, gentamicin, ticarcillin and ceftazidime [26], and it suppresses host immune response [27]. $\mathrm{AlgC}$ enzyme was found to be involved in the synthesis of alginate and lipopolysaccharide (LPS) (Figure 5A) [28]. The enzyme, encoded by alg $C$ gene, has both phosphomannomutase activity and phosphoglucomutase activity. The conversions of Man-6-P into Man-1-P and glucose-6-P into glucose1-P are catalyzed by this enzyme. Man-1-P is a crucial intermediate in the synthesis pathway of alginate and LPS [29]. Apart from alginate and LPS, Psl and Pel are also two major biofilm matrix exopolysaccharides. Pel and Psl are both important materials in mature $P$. aeruginosa biofilms. Psl polysaccharide is composed of a repeating pentamer consisting of D-mannose, L-rhamnose and D-glucose residues (Figure 6B) and it promotes the initial surface attachment process. Pel genes are responsible for glucose-rich exopolysaccharides formation in the strain PA14[22] and psl genes are involved in mannose-rich exopolysaccharides formation in strains ZK2870[23] and PAO1[24]. A psldeficient PAO1 strain could still form mature biofilm by upregulating pel genes [30]. It was shown that $\mathrm{AlgC}$ enzyme is also needed for the synthesis of Psl and Pel [28]. Man-1-P is a common intermediate in the synthesis of Psl, alginate and LPS, and the productions of these biofilm components were found to be influenced by each other (Figure 6A) [28]. That is, if one of them was over produced, then the production of the others would be reduced.

In total, there are 24 genes involved in the production and secretion of alginate in $P$. aeruginosa. Eight of them regulate the exportation of alginic acids, and 12 are responsible for the biosynthesis of the polysaccharide. The four remaining genes regulate the synthesis $[32,33]$.

In Staphylococcus, the biofilm-related exopolysaccharide is polysaccharide intercellular adhesin (PIA),

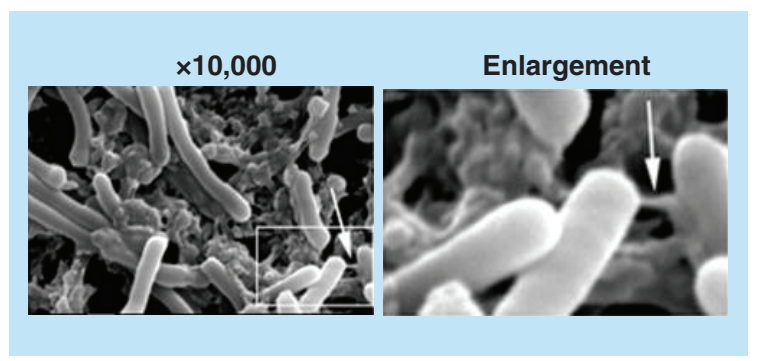

Figure 3. Scanning electron microscopy visualization of biofilm. The bacteria and the extracellular polymeric substance matrix were visualized by SEM at $\times 10,000$ magnification. The white box indicates the enlarged section, and the white arrow indicates the connections between bacteria in 3-day old biofilm (scale bar $=1 \mu \mathrm{m}$ ).

SEM: Scanning electron microscopy.

Reproduced from [14]. 

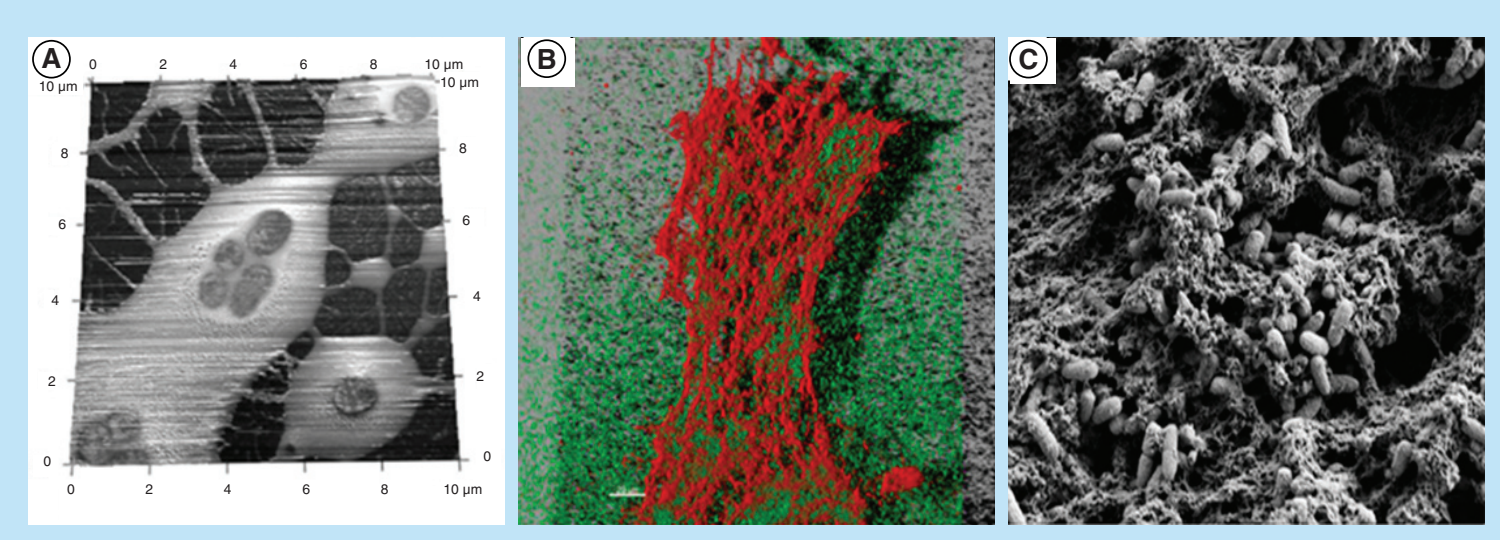

Figure 4. Extracellular polysaccharides in Escherichia coli and Pseudomonas aeruginosa. (A) Atomic force microscopy image of alginate in $P$. aeruginosa FRD1. (B) Confocal laser scanning microscopy image of Psl in hydrated $P$. aeruginosa PAO1. (C) SEM image of Pel in $P$. aeruginosa PA14.SEM: Scanning electron microscopy. Reproduced from [31].

which was characterized by Mack and coworkers [34]. PIA, also known as poly $N$-acetyl glucosamine, is a linear polymer composed of $\beta-1,6$-linked glucosamine residues. More than $80 \%$ of the PIA residues in Staphylococcus epidermidis are $N$-acetylated and the rest are positively charged [34]. Biosynthesis of PIA is conducted by four proteins: IcaA, IcaB, IcaC and IcaD. The $N$-acetylglucosaminyltransferases IcaA and IcaD synthesize 20 residue oligomers from UDP-GlcNAc. IcaC is involved in long oligomer formation (>130 residues) and transportation of the oligomers to the extracellular space. Deacetylation by IcaB results in positive charges, which is essential for interactions with cell membranes [35].

In Bacillus subtilis the biofilm-related exopolysaccharide can be EPS or poly- $\delta$-glutamate, depending on the strain and the conditions [36,37].

\section{Extracellular proteins}

Extracellular proteins are another major EPS matrix component [38]. Some proteins are attached to cell surfaces and polysaccharides to help with biofilm formation and stabilization. One example is the glucanbinding proteins (Gbps) in S. mutans biofilm [39]. Gbps play an important role in biofilm architecture maintenance by linking bacteria and exopolysaccharides. Biofilms produced by Gbps mutants have significantly reduced height.

Amyloids are also insoluble fibrous proteins that play a supportive role in biofilm architecture. One example is the Fap amyloids in Pseudomonas spp. Overexpression of Fap amyloids leads to cell aggregation and increased biofilm formation [40]. Amyloid protein TasA is one of the major components of B. subtilis biofilms [41]. TasA forms strong fibers that can hold biofilm cells together and tolerate harsh destructive forces. Another example is the biofilmassociated protein (bap) family. The bap family includes Bap protein from $S$. aureus [42] and Esp protein from E. faecalis [43]. The bap family is involved in biofilm formation and infection processes [44]. Other examples include outer-membrane lectins of Azospirillum brasiliense [45] and the galactophilic lectin le-cA [46] and L-fucose binding lectin lecB $[47]$ of P. aeruginosa.

Some enzymes are involved in degradation processes within biofilms. The enzymes' substrates include polysaccharides, proteins, nucleic acids, cellulose, lipids, other EPS matrix components and objects that are trapped in the EPS matrix. These enzymes can break down biopolymers and provide carbon and energy resources to biofilm cells, especially during starvation [48]. The detachment and dispersal of biofilm also require enzymatic functions. Degradation of EPS matrix internally by enzymes releases biofilm cells and initiate a new biofilm lifecycle. For example, DspB protein is responsible for the surface detachment of Actinobacillus pleuropneumoniae biofilms [49].

\section{eDNA}

Extracellular DNAs (eDNAs) were previously considered as leftovers from lyzed cells until Mattick and coworkers found that DNase I could prevent $P$. aeruginosa biofilm formation [50]. The fact that eDNA not only comes from lyzed cells but also is actively secreted [51] indicates that eDNA has an important role in biofilm formation. It is found to be critical for biofilm attachment (Figure 7). Its negative charge works as a repulse force in the initial attachment, but when the distance between cell and surface becomes a few nanometers, eDNA interacts with receptors on substratum surface to facilitate adhesion [52]. Also, eDNA was found to 


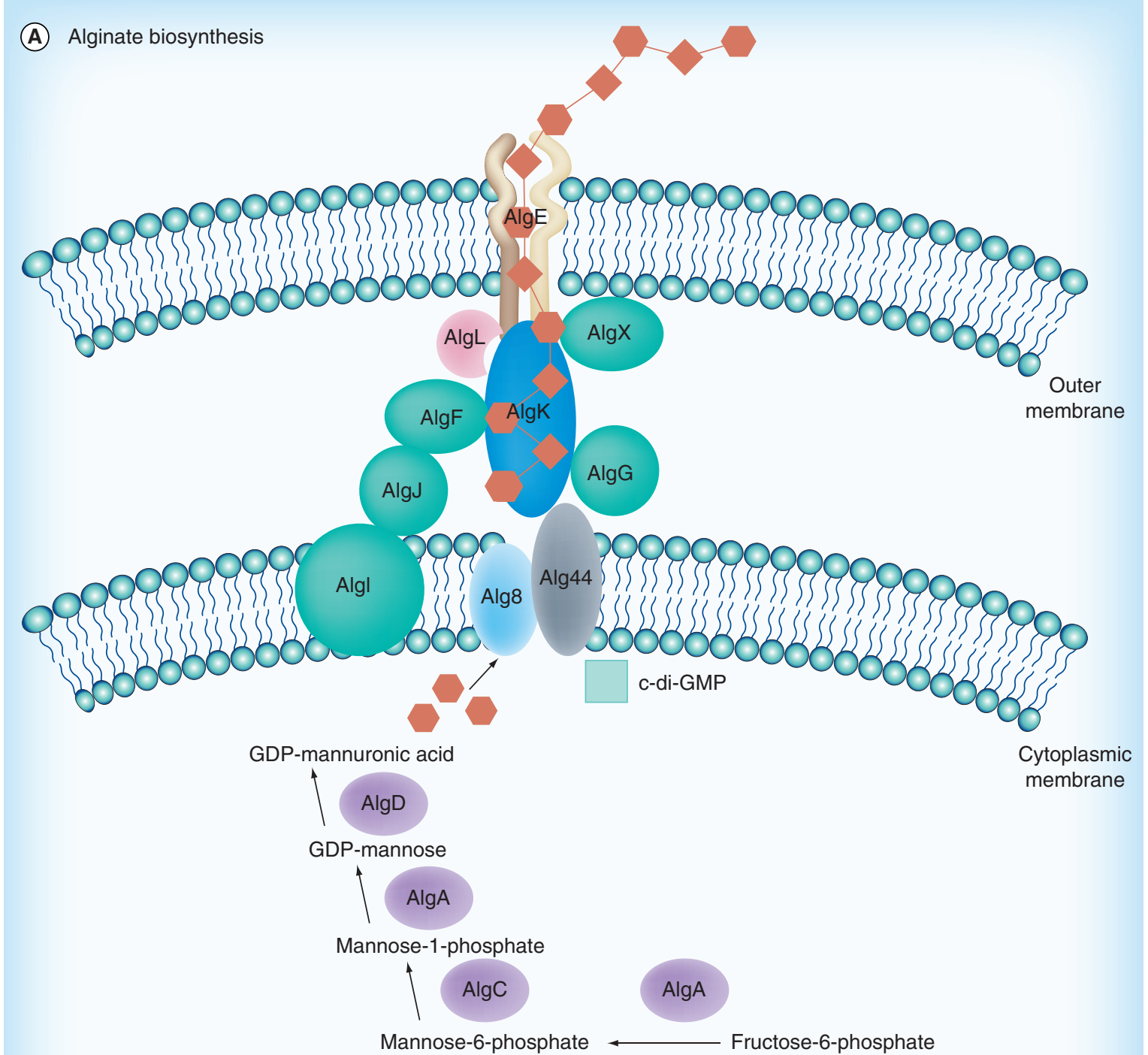

(B) Alginate structure

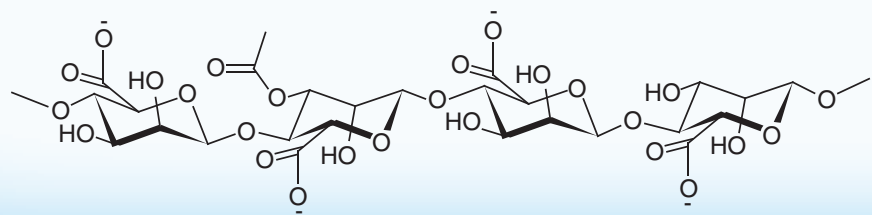

Figure 5. Alginate (A) biosynthesis and (B) chemical structure.

coordinate cell movement in the twitching motilitymediated $P$. aeruginosa biofilm expansion [53]. Due to its negative charge, eDNA is able to chelate metal cations and some positively charged antibiotics. eDNA can chelate $\mathrm{Mg}^{2+}$ and activate PhoPQ/PmrAB twocomponent systems, leading to antimicrobial peptide resistance in $P$. aeruginosa [54,55], Salmonella enterica serovar Typhimurium [56] and other Gram-negative bacteria. In S. epidermidis, eDNA was also found to inhibit the transportation of vancomycin within bio- films and hence protect the bacteria embedded within the biofilm [57,58].

The current knowledge about the roles that eDNA plays in biofilm maturation and persistence is limited and more research is warranted to shed light on its role in biofilm development.

\section{Reason for biofilm formation}

Many bacteria can switch between planktonic form and biofilm form. The planktonic bacteria have relatively 


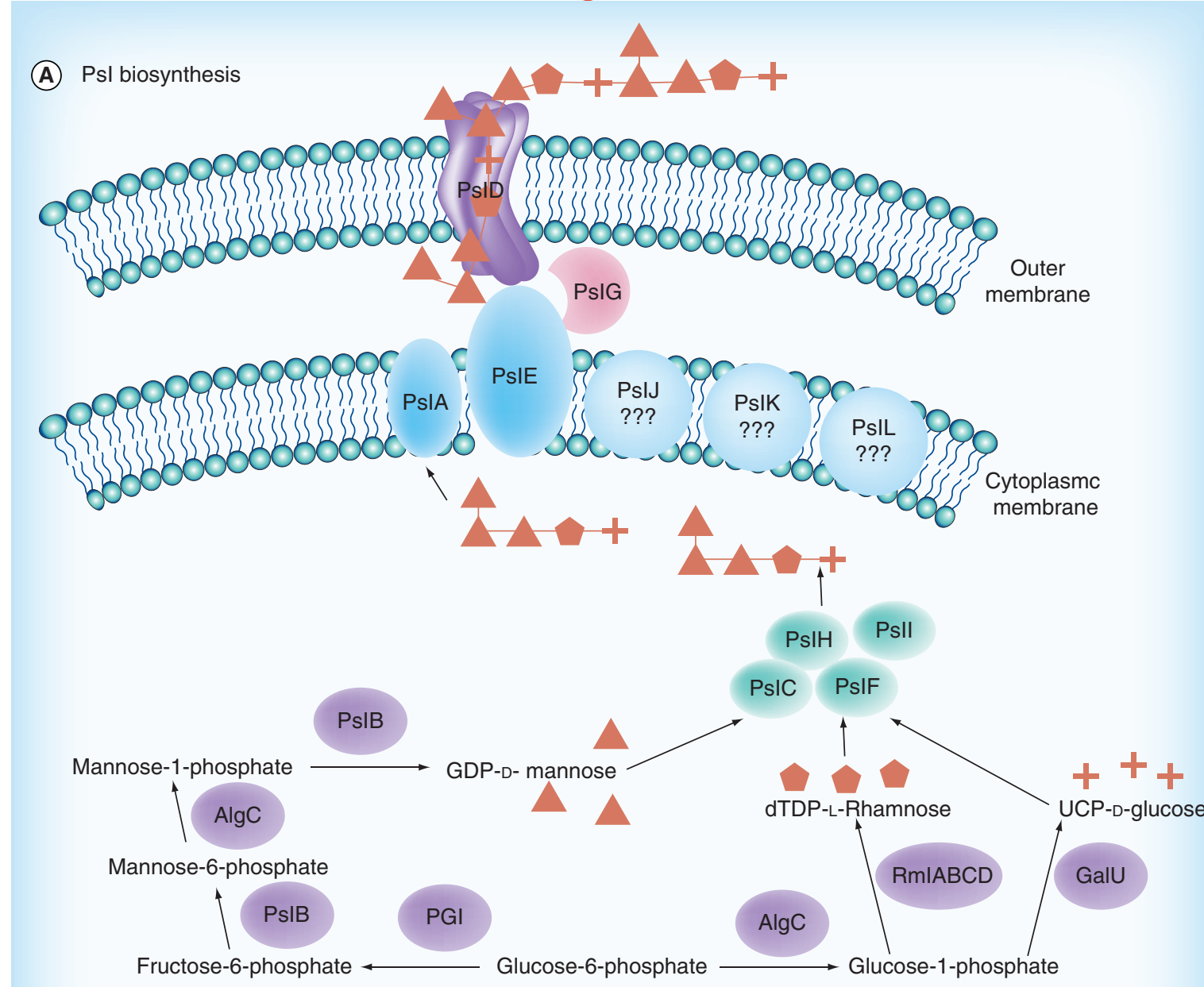

(B) Psl structure

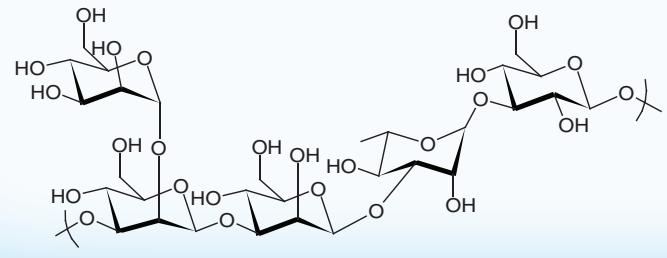

Figure 6. Psl (A) biosynthesis and (B) chemical structure.

high cell growth and reproduction rate. However, the biofilm state appears to be natural and predominant state of bacteria. Several reasons could account for the need for a bacterial biofilm state [60]. First, biofilm can enhance the tolerance of bacteria to harsh environmental conditions. Bacteria can avoid being washed away by water flow or blood stream by simply attaching to a surface or tissue. The oral biofilms can stand up to repeated, strong, shear forces. Cells in biofilms are about 1000 times more resistant than their planktonic [61]. Second, the EPS matrix protects bacteria cells, in deeper layers, against antimicrobial agents probably by limiting the diffusion of these agents. Biofilm restricts bacterial mobility and increases cell density, which also provides an optimal environment for eDNA (plasmid) exchange (via conjugation), some of which encode for antibiotic resistance. As reported by Hausner and Wuertz, the horizontal gene transfer rate is significantly higher in biofilms than in the planktonic cells [62].

\section{Process of biofilm formation}

A prerequisite of biofilm formation is that bacteria should get close enough to a surface. As bacteria 
approach a surface several forces, both attractive and repulsive, come into play. At about $10-20 \mathrm{~nm}$ distance from the surface, the negative charges on the bacterial surface are repelled by negative charges on most environmental surfaces [63]. This repulsion could, however, be overcome by attractive van der Waals forces between the bacterial cells and the surface as well as the use of fimbriae and flagella to provide mechanical attachment to the surface [63]. Biofilm formation can be described in three stages: attachment, maturation and dispersion (Figure 8).

The attachment step could be further categorized as a two-stage process: initial reversible attachment and irreversible attachment [64]. The irreversible attached biofilm can tolerate stronger physical or chemical shear forces. [65] In the initial attachment, flagella and type IV pili-mediated motilities are important. Flagella are critical for initial interactions between cells and surface. Type IV pili-mediated twitching motilities enable attached cells to aggregate and form microcolonies. O'Toole and Kolter demonstrated that $P$. aeruginosa flagella-deficient mutants could not land onto surfaces and type IV pili-deficient mutants could not form microcolonies [66].

For the human pathogens S. epidermidis and $S$. aureus the initial step of biofilm formation is the attachment to human matrix proteins, such as fibronectin (Fn), fibrinogen $(\mathrm{Fg})$, vitronectin $(\mathrm{Vn})$, etc. Microbial surface components recognizing adhesive matrix molecules dependent adhesions are covalently linked to the peptidoglycan on the cell wall. $S$. aureus has more than 20 microbial surface components recognizing adhesive matrix molecule genes while S. epidermidis RP62A has only 12 [67]. Noncovalent adhesions, such as those mediated by autolysins, also contribute to initial attachment of biofilms [68].

The production of EPS matrix signifies the irreversible phase of bacterial attachment to a surface. The EPS matrix of $P$. aeruginosa has been well studied, probably due to the role that $P$. aeruginosa biofilms play in the progression of cystic fibrosis. Alginate, a major polysaccharide component of $P$. aeruginosa EPS matrix, is produced by bacteria that are attached to a surface (recently attached bacteria) in quantities that are several folds more than by planktonic cells [69]. The $\sigma$ factor AlgT, which is also required for alginate production, downregulates flagella genes [70].

Once the first layer of the biofilm is established, cells of the same species or other species are recruited to the biofilm from the bulk fluid. Biofilm grows from a thin layer to a 'mushroom' or 'tower' shape structure. In a thick biofilm (>100 layers), bacteria are arranged according to their metabolism and aero tolerance. For example, anaerobic bacteria prefer to live in deeper lay-

\section{Key terms}

Planktonic cells: Bacteria that float or swim as single cells.

Dispersion: The release of planktonic cells from the biofilm as a result of unfavorable conditions for the biofilm form. This is the final step in biofilm development, from a mature biofilm to the planktonic form. Usually few parts of the biofilm are dispersed and it is a continuous process. This step allows the biofilm to spread and colonize on a new surface.

ers to avoid exposure to oxygen. Bacteria within biofilm communities 'talk' to each other and take specialized functions. As the biofilm matures, more biofilm scaffolds, such as proteins, DNA, polysaccharides, etc. are secreted into the biofilm by the entrapped bacteria.

After biofilm maturation the dispersal step, which is also critical for the biofilm life cycle, follows. Biofilms disperse because of myriads of factors, such as lack of nutrients, intense competition, outgrown population, etc. Dispersal could occur in the whole biofilm or just a part of it. Release of planktonic bacteria promotes the initiation of new biofilms at other sites.

\section{Biofilm-related diseases}

Biofilms are linked to various human diseases [71]. Many bacterial infections are biofilm related, for example, chronic lung, wound and ear infections [72]. Bioflms are also able to colonize on medical devices such as catheters and implants. According to the NIH more than $80 \%$ of all microbial infections are biofilm related [73]. These kinds of infections are hard to diagnose and treat.

\section{Cystic fibrosis}

Cystic fibrosis (CF) in the lung causes the formation of thick and sticky mucus, which blocks airway and

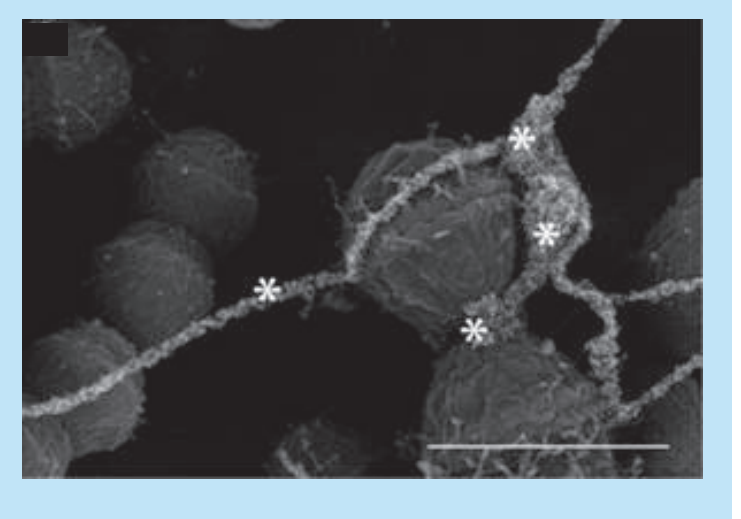

Figure 7. Extracellular DNA in Enterococcus faecalis biofilm. Visualization of labeled strands by using an anti-dsDNA monoclonal antibody conjugated to an immunogold particle (asterisks; scale bar $=250 \mathrm{~nm}$ ). Reproduced from [59]. 


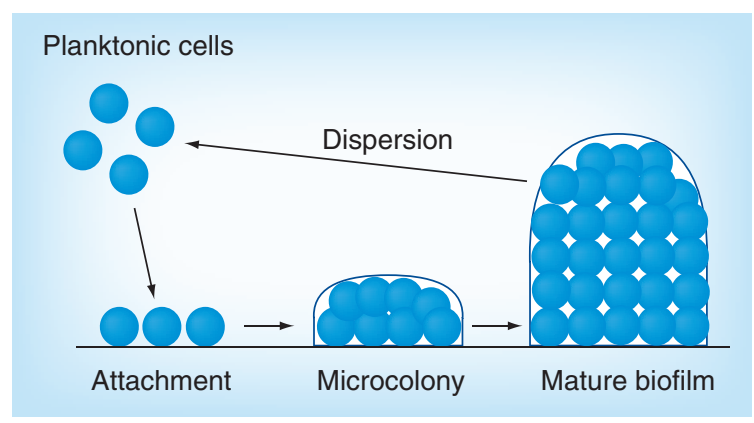

Figure 8. Biofilm formation process.

makes it hard for patients breath [74]. Eighty percent of CF patients are chronically infected by $P$. aeruginosa. Medical instruments, devices and tools can also be contaminated with $P$. aeruginosa. Several cases of hospital-acquired $P$. aeruginosa infections have been reported [75,76], but unfortunately, there are not many good antibiotics that are available for treating recalcitrant $P$. aeruginosa infection [77]. For patients who are infected with $P$. aeruginosa, antibiotic treatment often relieves the symptom of the infection but not necessarily cures the infection. The lack of complete cure is mainly due to $P$. aeruginosa biofilms that act as reservoirs for disease recurrence [78]. This calls for the development of drugs that can act on $P$. aeruginosa biofilms. These future drugs could either kill the bacteria in the biofilm or cause the dispersal of the biofilm into planktonic state and by that enabling drugs that work on planktonic bacteria to take effect [79]. Beyond acting as disease reservoirs, the components of biofilms, such as the major polysaccharide of $P$. aeruginosa matrix (alginate), are virulence factors. For example, alginate can cause lung damage [80].

\section{Dental plaque}

Biofilms play an important role in dentistry and there have been many studies on dental biofilms [81,82]. Over 700 species of bacteria and archaea have been reported to exist in dental plaque [83,84]. Dental plaque is actually composed of mixed biofilms [85]. However, the composition of the healthy plaque biofilm is significantly different from disease-associated plaque biofilms.

The mouth is a unique microenvinronment that is characterized by water, temperature fluctuations, hard surface, and carbon and nitrogen input. Changes in the local environment influence the biofilm bacterial composition. Acid is a major cause of tooth decay and innocuous bacteria species in healthy biofilms, including Streptococcus sanguis, Streptococcus gordonii, Streptococcus oralis, Actinomyces species, etc. often show low acid tolerance [86]. On the contrary, bacteria involved in dental caries, such as $S$. sobrinus and $S$. mutans, have very high acid tolerance. These acid-tolerant bacteria that can also form robust biofilms are responsible for many oral cavity diseases, such as dental caries, periodontitis, gingivitis, etc. [87].

Communication among bacteria is essential for initial colonization and successive biofilm formation on the enamel surfaces. If bacteria do not retain on the tooth surface, the bacteria are washed with the mouth fluid. If they do manage to hold to the surface, they organized as a multispecies to form a dental plaque. Oral microorganisms adhere to surfaces such as teeth, epithelial tissues or to other bacteria that is immobilized on the surface (coadhesion). Cell-cell interaction between genetically distinct cells can also occur in suspension (coaggregation). Oral bacteria have at least one coaggregation partner. A diagram illustrating competition and co-operation among early and late colonizers of the tooth is shown in Figure 9. The initial colonizers are streptococci and actinomyces [88,89]. Receptors are recognized by the primary colonizers of dental plaque. Among the receptors are found phosphate-rich proteins such as statherin, and enzymes such as $\alpha$-amylase. Streptococci recognize receptors in the salivary pellicle (coats the enamel). Actinomyces bind to proline-rich proteins and statherin (Figure 9). Fusobacteria, anaerobic Gram-negative bacteria, also bind to statherin.

Bacteria communicate in the oral biofilm through the secretion and accumulation of small molecules. Autoinducer (AI)-2 is a universal intergeneric signaling molecule that plays an important role in biofilm development [91,92]. AI-2 stimulates the coaggregation of $S$. oralis and Actinomyces oris T14V. Small concentrations of AI-2 are sufficient for coaggregation of oral bacteria, less for oral pathogens. As the cell density of the commensal bacteria increases, the AI-2 concentration increases. At the highest concentration, the pathogens grow and develop the biofilm. At low concentration the conditions do not support their growth. Fusobacteria produce high levels of AI-2, then coaggregate with variety of colonizers and become dominant bacteria in biofilms associate with healthy gums and plaque.

\section{Wounds}

Biofilms are commonly found in chronic wounds [93]. Compared with an acute wound, which is usually not associated with biofilm, a biofilm-related chronic wound persists and only slowly heals. Biofilms usually form on the outer layer of wounds but some biofilms are also embedded in the deep layers of a wound, such as $P$. aeruginosa biofilms, and they are difficult to diagnose using a traditional wound swab culture [71].

\section{Urinary infection}

Biomaterials in the urinary tract, such as catheters, increase the chance of bacterial biofilm formation, 


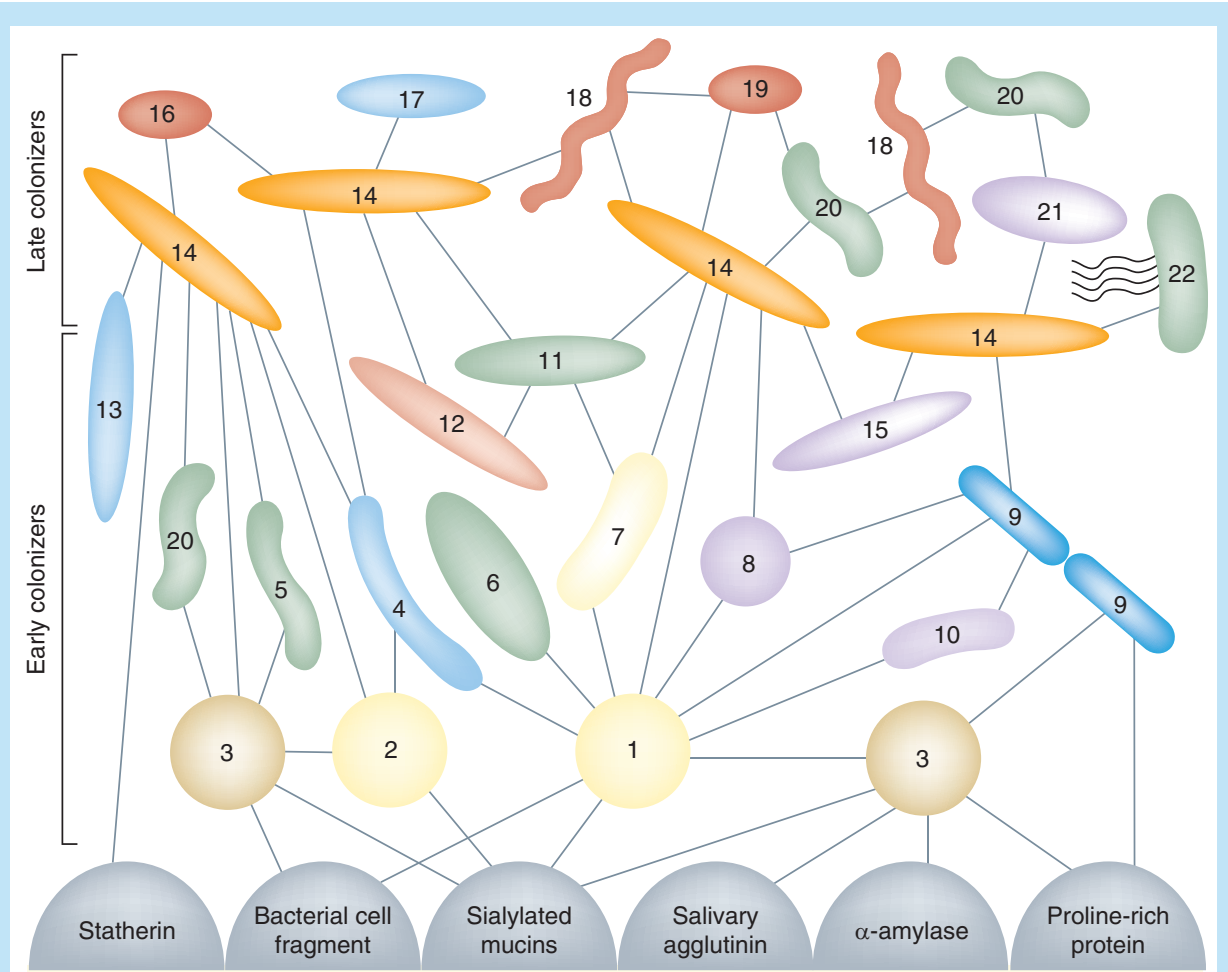

1. Streptococcus oralis and

Streptococcus sanguinis

2. Streptococcus mitis

3. Streptococcus gordonii

4. Capnocytophaga ochraccea

5. Propionibacterium acnes

6. Haemophilus parainfluenzae

7. Prevotella loescheii

8. Veillonella spp.

9. Actinomyces oris and

Actinomyces naeslundii

10. Eikenella corrodens

11. Actinomyces israelii

12. Capnocytophaga gingivalis

13. Capnocytophaga sputigena

14. Fusobacterium nucleatum

15. Prevotella denticola

16. Aggregatibacter

actinomycetemcomitans

17. Eubacterium spp.

18. Treponema denticola

19. Tannerella forsythia

20. Porphyromonas gingivalis

21. Prevotella intermedia

22. Selenomonas flueggei

Salaivary pellicle

Tooth surface

Figure 9. Oral bacterial colonization. Spatiotemporal model of oral bacterial colonization showing recognition of salivary pellicle receptors by initial colonizing bacteria and coaggregations between initial colonizers, fusobacteria and late colonizers of the tooth surface. Collectively, these interactions are proposed to represent development of dental plaque. Starting at the bottom, initial colonizers, Streptococcus gordonii, Streptococcus mitis, Streptococcus oralis and Streptococcus sanguinis, bind to complementary salivary receptors (sialylated mucins, proline-rich protein, $\alpha$-amylase, salivary agglutinin and bacterial cell fragments) in the acquired pellicle coating the tooth surface. Late colonizers bind to previously bound bacteria. Sequential binding results in the appearance of nascent surfaces that bridge with the next coaggregating partner cell. Coaggregation is different from aggregation that occurs between genetically identical cells and from agglutination of cells through interaction of cells with soluble molecules, for example, antibodies. Most coaggregations are between cells of different genera; Fusobacterium nucleatum strains, for example, coaggregate intergenerically with representatives of all oral bacterial species. However, intrageneric coaggregation among fusobacterial strains is only rarely observed. In sharp contrast, streptococci exhibit broad intrageneric coaggregation partnerships (e.g., S. gordonii and S. oralis) as well as intraspecies partnerships (e.g., S. gordonii DL1 and S. gordonii 38). Each bacterial strain exhibits specificity in partners. For example, some streptococci are capable of coaggregating with certain Veillonella spp., whereas other streptococci cannot coaggregate with those veillonellae but do coaggregate with a separate group of veillonellae.

Reproduced with permission from [90] @) Macmillan Publishers Ltd (2010).

leading to urinary infection [94]. The synthetic foreign body provides surfaces for bacteria to attach. Almost all urinary catheters (both the inner and outer surfaces) are infected with bacterial biofilms (Figure 10). These biofilms, for example, P. mirabilis biofilms, which can be crystalline in nature, can block catheters and patients have to replace the blocked catheters [95].

\section{Prosthetic joint infection}

Bacteria causing prosthetic joint infection are usually Gram-positive, such as staphylococci [96]. Most often immediately after surgery, bacteria (which could come from blood or the lymph) attach to the surface of prosthetic joints to form biofilms. Unlike typical bacterial infections that give symptoms like fever, it could take a while before symptoms of the biofilms on these implants, such as pain, emerge [97].

\section{Cardiac valve infection}

Bacterial biofilm on mechanical cardiac valve causes a disease called prosthetic valve endocarditis. The species involved in endocarditis are S. epidermidis, S. aureus, Streptococcus spp., Corynebacterium spp., Enterococcus spp. and Candida spp [98]. Accumulated biofilm can disrupt or block the artificial cardiac valve, resulting in diminished flow, turbulence or even leaking. Detached biofilm cells can migrate along with the blood stream and cause infection in other organs. Biofilm fragments in the blood circulation can block blood at the terminal 


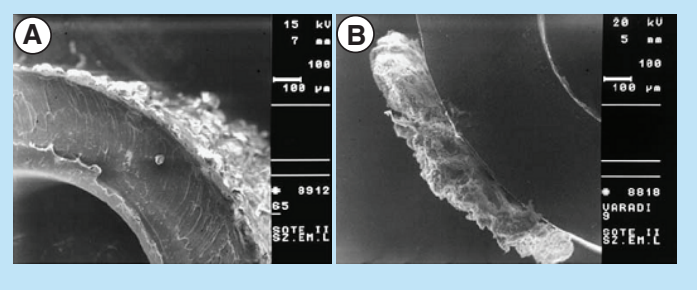

Figure 10. Biofilm on urethral stents. Scanning electron microscopic picture of a developing biofilm on urethral stents that is lying completely within the urinary tract. Reproduced with kind permission from [94] @ Springer Science and Business Media (2006).

points, such as the brain and kidney.

\section{Biofilm resistance to antibiotics \& host immune system}

Bacteria in a biofilm are more resistant to antibiotics or the reactive molecules that are produced by the host immune systems than planktonic bacteria. It has been estimated that biofilm cells can be up to 10,000 times more resistant to antibiotics than planktonic cells $[99,100]$. Costerton and coworkers observed that when they treated $P$. aeruginosa biofilm and planktonic cells with tobramycin, planktonic cells could not survive greater than $50 \mu \mathrm{g} / \mathrm{ml}$ tobramycin, but biofilm cells could tolerate $1 \mathrm{mg} / \mathrm{ml}$ tobramycin [100]. Abee and coworkers also reported that with two different disinfectants, benzalkonium chloride and the oxidizing agent sodium hypochlorite, the effective inhibitory concentrations on $S$. aureus biofilms are 50- and 600-times higher than planktonic cells, respectively [101]. The reason(s) for increased antibiotic resistance by bacterial biofilms is/are not yet fully understood. It is highly probable that multiple factors work together to protect biofilm cells from antibiotic treatment. Some of the possible mechanisms for antibiotic resistance exhibited by bacterial biofilms are as follows.

\section{Limited antibiotic penetration}

As previously described, EPS matrix plays an important role in antibiotic resistance by limiting antimicrobial agents' penetration into the biofilm. Charged polysaccharides and eDNA can trap several kinds of antibiotics. The penetration property of antibiotics has been measured by the concentration at the base of the biofilm by Suci and coworkers. Results showed that ciprofloxacin concentration in $P$. aeruginosa biofilm was dramatically reduced, but not completely blocked [102]. Steward and coworkers investigated the penetration limitation of ampicillin and ciprofloxacin on $K$. pneumoniae. Ciprofloxacin has a much better penetration capability than ampicillin. As a result, biofilm cells could tolerate concentrated ampicillin but their resistance to ciprofloxacin is poor [103].

\section{Horizontal gene transfer}

Some bacteria can acquire antibiotic resistance via random mutations on genes. Others also harbor antibiotic-resistant genes on plasmids. Plasmids can be easily passed on to other cells by horizontal gene transfer. In biofilms, the frequencies of horizontal plasmid transfer are much higher than between planktonic cells. Studies on $S$. aureus biofilms showed that biofilms promote the spread of plasmid-borne antibiotic resistance genes by conjugation/mobilization [104].

\section{Reduced growth rate}

There is limited availability of oxygen and nutrients inside biofilms, so biofilm cells, especially those in the deep layers, have a slow metabolic rate, as well as growth rate and division rate. These features make biofilm bacteria insensitive to antibiotic drugs that target dividing cells. For example, the targets of $\beta$-lactams are dividing cells, so when they are used on E. coli biofilms, their bacteriolytic activity is diminished [105].

\section{Persister cells}

In biofilms, there is a small subpopulation of cells called persister cells $[106,107]$. Their growth rate is zero or extremely slow. Most of the antibiotics that are currently used in the clinic, which target processes that are relevant for cell growth or division, are not effective against persister cells. Therefore, these cells act as disease reservoirs that could reactivate into infectious particles once the antibiotic stress has been removed.

\section{Efflux pumps}

Efflux pumps allow bacteria cells to pump intracellular toxins out, including antibiotic drugs. Efflux pumps are also expressed in planktonic cells, but some efflux pump genes are upregulated in biofilm, indicating that they contribute to antibiotic resistance. Zhang and coworkers identified a novel $P$. aeruginosa efflux pump gene PA1874-1877 and the expression level of PA1874-1877 gene in biofilm is much higher than in planktonic cells [108]. Efflux pump encoded by this gene increases the resistance to tobramycin, gentamicin and ciprofloxacin.

\section{EPS matrix protection}

EPS matrix provides physical protection to the aggregated biofilm cells. Lei and coworkers showed that exopolysaccharide alginate in $P$. aeruginosa biofilms kept biofilm bacteria from human leukocyte killing [109]. 


\section{Signaling in biofilm formation Quorum sensing}

In order to form a biofilm, bacteria have to synchronize their gene expression and some use quorum-sensing (QS) systems to achieve this. QS is a mechanism by which bacteria apparently monitor cell density and regulate collective behaviors [110]. It is worth pointing out that the issue of bacterial population monitoring via $Q S$ is still hotly debated and many alternative hypotheses have been proposed for the role of molecules that are involved in QS [111]. Bacterial populations coordinate their gene expression by producing and responding to a variety of intra and intercellular signals termed 'autoinducers' [112]. Bacteria 'talk' to each other using chemicals for 'words' including small molecules (Figure 11A). For example, acyl-homoserine lactones (AHLs) mediate QS in Gram-negative bacteria. There are several types of AHL, depending on the length and functionalization of the acyl side chain. Small peptides regulate QS-mediated gene expression in Gram-positive bacteria and AI-2 mediate QS in both Gram-positive and Gram-negative bacteria, although its role in cell signaling is still controversial [113]. At low cell densities, a small amount of autoinducer is present in the extracellular media; however, it is too dilute to be detected. As cell density increases, the autoinducer concentration reaches a threshold and at this point the autoinducer/regulatory protein (the receptor)

\section{Key term}

Quorum sensing: Cell - cell communication process that regulates gene expression at high cell density. At high cell density the concentration of an autoinducer, which is secreted by the bacteria to the environment, reaches to a certain threshold, which leads to gene expression and regulation of diverse physiological activities.

complex acts to induce or repress expression of target genes (Figure 11B) [114]. QS controls diverse physiological processes: for example, bioluminescence, secretion of virulence factors, biofilm formation, antibiotic resistance and more. QS has been shown to regulate bioflm formation in several bacterial species [115].

In PAO1 strain of $P$. aeruginosa, AHL QS systems are responsible for eDNA release and for biofilm structure [116]. In PA14 strain, the QS system regulates the production of PEL exopolysaccharide [117]. In S. aureus, the QS system regulates biofilm dispersal. The QS molecule in $S$. aureus is a peptide (AIP) derived from the product of the agr $D$ gene, which is then detected by AgrC and activate the regulator AgrA. AgrA regulates the transcription of genes that code proteases that are involved in biofilm dispersal [118,119]. In B. subtilis, the QS molecule surfactin is important for biofilm formation [120]. Surfactin causes potassium leakage from the cytoplasm which triggers the expression of the genes involved in extracellular matrix production.
(A)

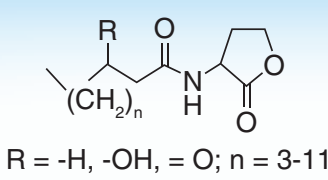

AHLs

(B)

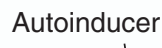

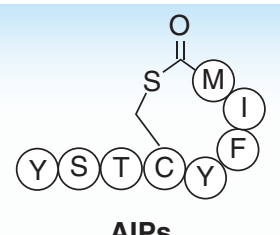

AIPs

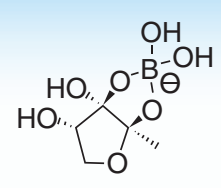

Al-2

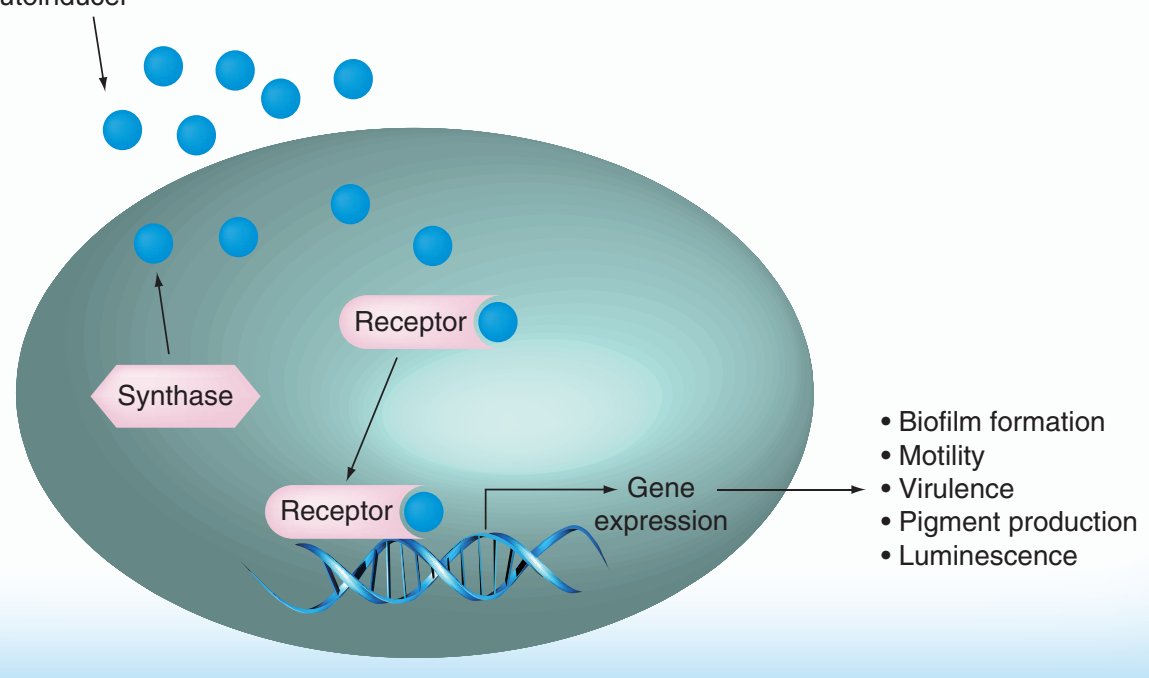

Figure 11. Quorum sensing. (A) Main quorum-sensing autoinducers. (B) Quorum-sensing circuit. AHL: Acylhomoserine lactone; AIP: Autoinducing peptide; Al: Autoinducer. 


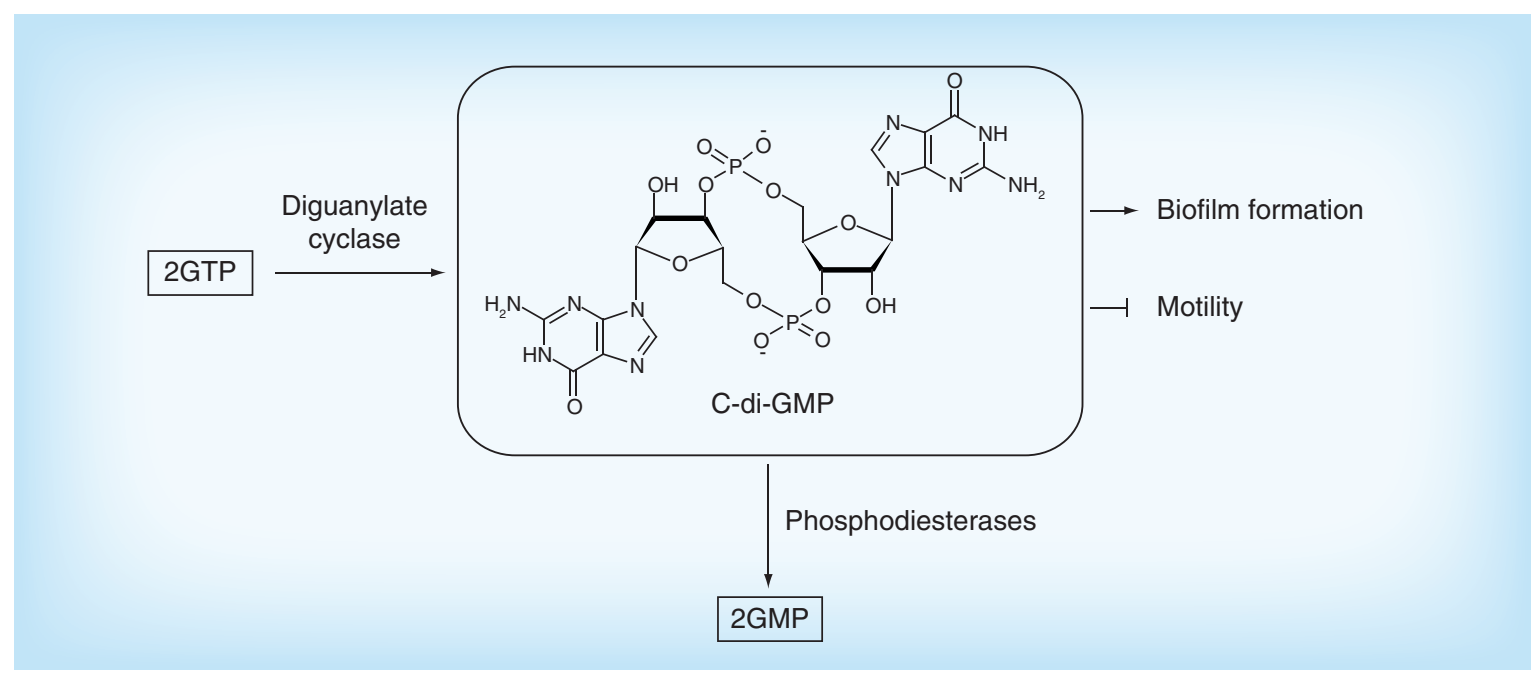

Figure 12. Cyclic dinucleotide signaling pathway.

\section{c-di-GMP}

C-di-GMP has emerged as an important second messenger involved in biofilm formation. It was originally found to allosterically activate cellulose synthase in Acetobacter xylinus [121,122]. This signaling molecule has been found to modulate a variety of bacterial growth phenotypes including but not limited to biofilm formation, motility and virulence factor production [123]. In the cell, c-di-GMP is synthesized from two GTP molecules by diguanylate cyclases characterized by a GGDEF domain, a set of highly conserved active site residues, whereas the second messenger is degraded into $\mathrm{pGpG}$ or GMP by phosphodiesterases (PDEs) containing EAL domain or HD-GYP domain, respectively (Figure 12) [122,124-127]. These enzymes function in concert to regulate the intracellular c-di-GMP levels.

The correlation between intracellular c-di-GMP concentration and biofilm formation has been observed in several clinically relevant bacteria (Table 1). For a detailed review of how fluctuating levels of cellular
c-di-GMP affect biofilm formation and some effector systems involved, the reader is referred to an excellent review by Boyd and O'Toole [128]. Briefly, in most bacteria the transition from motile to sessile mode of life is regulated by various effector proteins that bind c-di-GMP resulting in varying outputs via cell-surface protein localization, protein-protein interaction, transcriptional activation and DNA binding [128]. In $P$. fluorescens, biofilm formation is initiated when an inner membrane effector protein, LapD binds cellular c-diGMP to facilitate the transport of the biofilm adhesion LapA to the cell surface $[129,130]$. Other studies have revealed that in the presence of RapA PDE (suggesting decreased cellular c-di-GMP levels), the secretion of LapA is inhibited and hence biofilm formation is abolished [131]. A protein-protein interaction was observed in E. coli, with YcgR protein integrating cellular c-diGMP levels and interacting with components of the flagellar motor to modulate motile-to-sessile transition [132-134]. Other studies showed that a VieS/VieA

Table 1. Clinically relevant bacteria that use c-di-GMP second messenger.

\begin{tabular}{|llr|}
\hline Bacteria & Diseases & Ref. \\
\hline Vibrio cholerae & Cholera & {$[127]$} \\
\hline Pseudomonas aeruginosa & Pulmonary and urinary tracts infections & {$[137]$} \\
& $\begin{array}{l}\text { Burn injuries infections } \\
\text { Blood infections }\end{array}$ & {$[138]$} \\
\hline Yersinia pestis & Plague of Justinian & \\
& Black Death & {$[139]$} \\
\hline Klebsiella pneumoniae & Third Pandemic & {$[140]$} \\
\hline Legionella pneumophila & Pneumonia & {$[141]$} \\
\hline Vibrio vulnificus & Urinary tract & Lower biliary tract Wound infections \\
\end{tabular}


sensor kinase/response regulator pair function to reduce cellular c-di-GMP concentration and inhibit biofilm formation in Vibrio cholerae [135]. It was determined that VieA PDE degraded c-di-GMP when phosphorylated by VieS sensor kinase. The decreased cellular c-di-GMP concentration was concomitant with a repressed expression of $v p$ s (vibro exopolysaccharide sysnthesis) genes, responsible for EPS synthesis and biofilm formation in $V$. cholerae $[135,136]$. Previous studies also observed an increased $v p s$ gene expression and subsequent induction of biofilm formation either by overexpression of putative diguanylate cyclases or inactivation of VieA PDE; both of which correspond to a high cellular c-di-GMP concentration [127].

\section{sRNAs}

Small noncoding RNAs (sRNAs) also play an important role in the bacterial regulatory networks controlling the switch between planktonic mode and biofilm mode. The regulatory functions of sRNAs are achieved by base pairing with other RNAs or binding with proteins. After Romeo and coworkers found the RNA-binding proteins CsrA and sRNA CsrB and revealed their roles in $E$. coli biofilm formation and dispersal [142-144], more sRNAs have been identified to participate in the biofilm regulatory networks in many bacteria.

One well-studied example is $P$. aeruginosa GAC signal-transduction network (Figure 13). GacS is a transmembrane sensor kinase, which induces the phosphorylation of its cognate regulator, GacA. GacA phosphorylation is also promoted by sensor kinase LadS and blocked by RetS [145]. Phosphorylated GacA stimulates the production of two sRNAs: RsmY and RsmZ [146]. RsmY and RsmZ have multiple binding sites for the regulatory protein RsmA. As a translational repressor, RsmA binds to the target mRNAs to promote bacterial motility and repress biofilm formation. Sequestration of RsmA by sRNAs RsmY and RsmZ switches planktonic mode to biofilm formation.

The first identified global biofilm regulator is CsrA [142]. The structure of CsrA regulatory network in $E$. coli is similar to the previously described RsmA system. CsrA's target mRNA binding ability is inhibited by two sRNAs, CsrB and CsrC. In the absence of CsrB and CsrC sRNAs, CsrA represses mRNA translation and leads to increased cell motility. CsrB and CsrC sRNAs trap CsrA, enable mRNA translation and promote biofilm formation [148].

Another master biofilm regulator in $E$. coli and S. Typhimurium is CsgD. CsgD regulation is at transcriptional level, by selectively activating curli fimbriae and extracellular polysaccharides genes and repressing flagella genes [149]. The activity of CsgD is under the regulation of sRNAs (McaS, RprA,

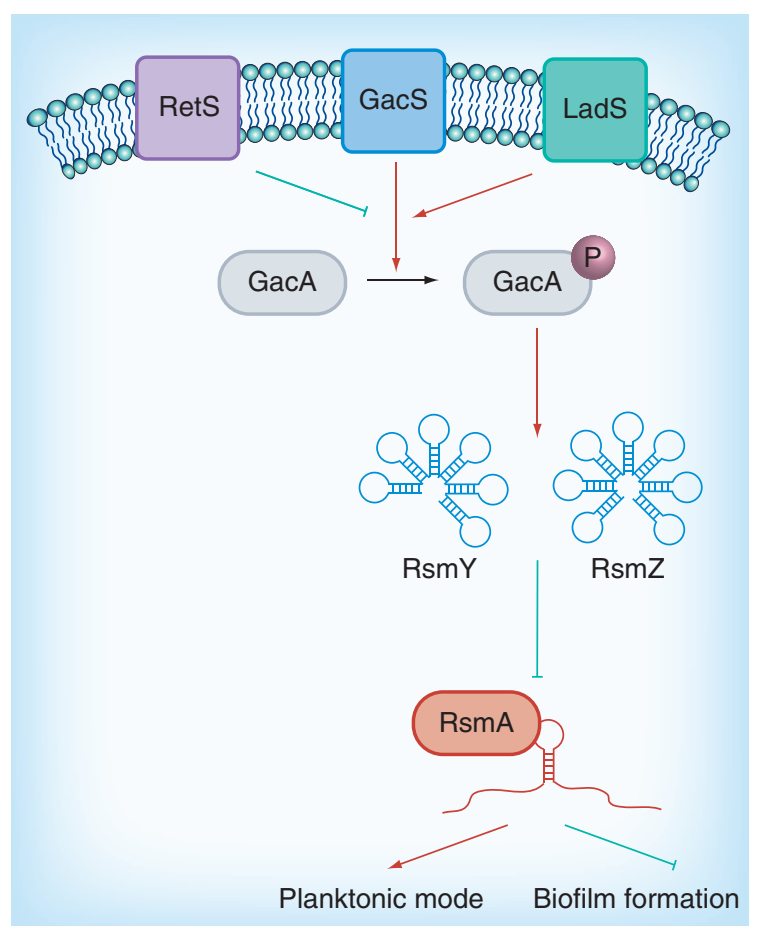

Figure 13. Pseudomonas aeruginosa GAC regulatory network. The phosphorylation of regulatory protein GacA is activated by GacS and LadS, but inhibited by RetS. Phosphorylated GacA promotes the production of two sRNAs, RsmY and RsmZ. RsmY and RsmZ sequester RsmA and block its mRNA-binding function. In the absence of RsmY and RsmZ, RsmA binds to target mRNA, prevents translation and resulted in increased cell motility and decreased biofilm formation. Adapted from [147].

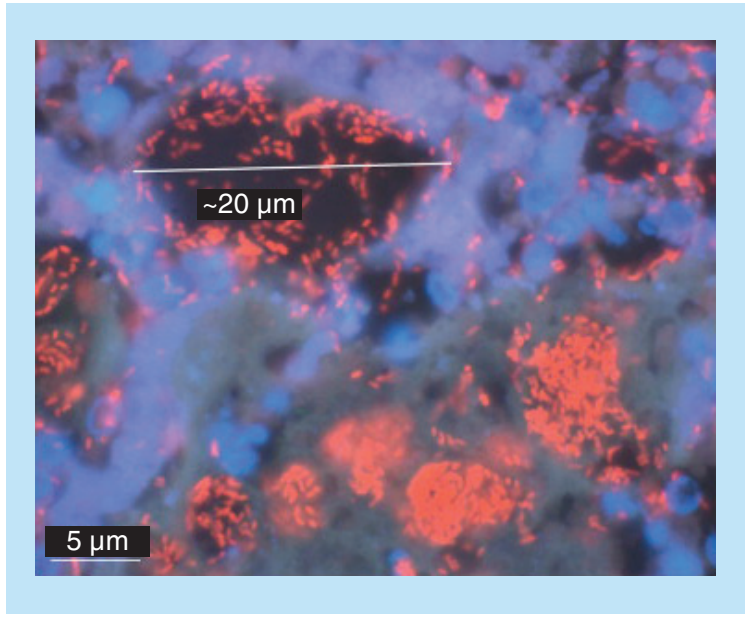

Figure 14. Biofilm aggregates of Pseudomonas aeruginosa in a chronic infected cystic fibrosis lung.

Using a specific $P$. aeruginosa PNA fluorescence in situ hybridization probe, the bacteria are visualized in red, whereas the inflammatory cells surrounding the biofilm patches are counterstained with 4',6-diamidino-2phenylindole, DAPI (blue).

Reproduced with permission from [158] () Wiley-Liss, Inc. (2009). 

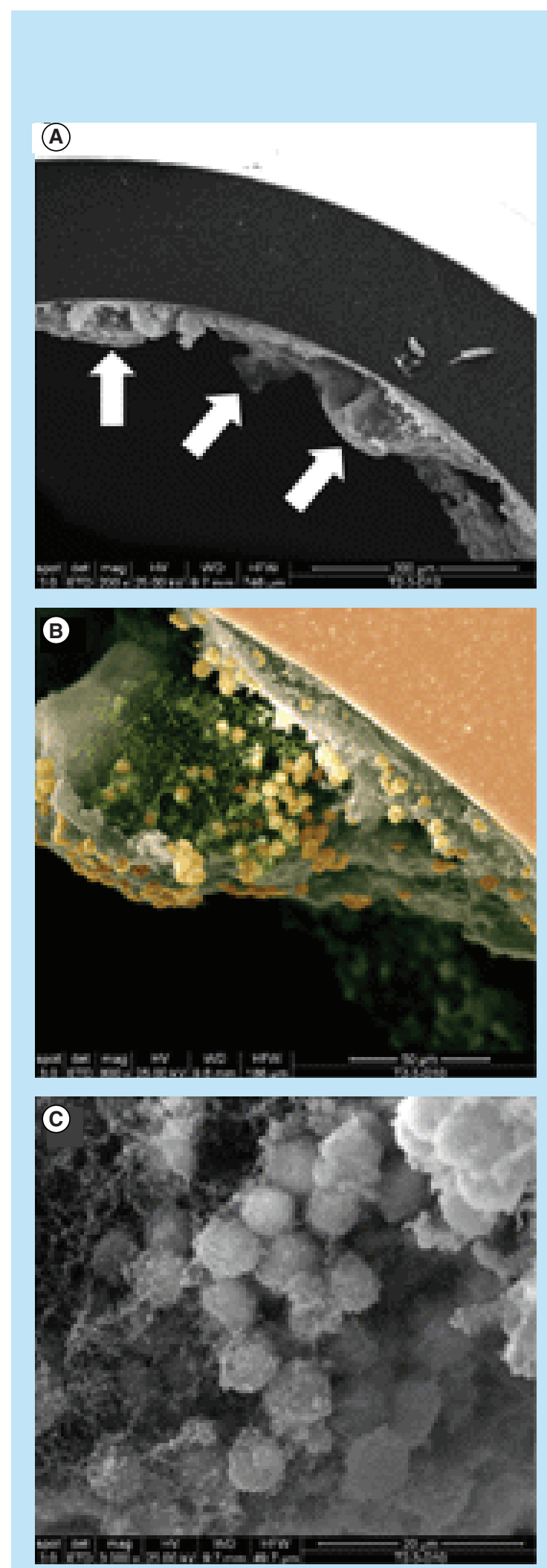

Figure 15. Evidence of catheter-associated biofilm growth in vivo. (A) Original magnification $\times 200$ demonstrating the irregular undulating pattern of the biofilm surface. (B) Higher magnification of a tower from the image shown in $(A)$ revealing a predominantly hollow interior with numerous cocci at the margins (original magnification $\times 800$ ). The image has been pseudocolored to highlight Staphylococcus aureus (gold) and presumably matrix material (green), which likely aggregated during the SEM dehydration process, from remaining biofilm structure (gray). The smooth surface at the upper right represents the catheter (salmon) with biofilm visible on the internal face. (C) Original magnification $\times 3000$ of an Staphylococcus aureus cluster within the tower depicted in (B). SEM:Scanning electron microscopy. Reproduced with permission from [7] () The American Association of Immunologists, Inc. (2011).

OmrA/OmrB, GcvB, etc.). These sRNAs are produced in response to different environmental conditions. Some sRNAs act as $\mathrm{CsgB}$ repressors, such as $\mathrm{OmrA} / \mathrm{OmrB}$, but some are $\mathrm{CsgB}$ activators, such as $\operatorname{ArcZ}$ [150].

For more detailed information, the reader is referred to a more thorough review of the role of small regulatory RNAs and biofilm formation by Chambers and Sauer [151].

\section{Biofilms in vivo}

The dynamics of the microenvironment in vivo is different from that seen in vitro. This raises the question of whether observations from in vitro experiments are directly amenable to in vivo studies. It is therefore important to study biofilms in vivo. Animal models such as mice [152,153], rabbits [154] and rats [155] have been used to investigate the effects of biofilm-mediated infections. It is important to note that these models may not exactly depict conditions in a human host but can provide good predictive power.

One of such infection caused by $P$. aeruginosa is the catheter-associated urinary tract infection. Cole et al. demonstrated that the biofilms formed in a murine model of catheter-associated urinary tract infection were independent of extracellular polysaccharides [156]. This observation was achieved by using mutant PA14 and PAO1 strains, which lacked the ability to produce exopolysaccharides. The biofilm formed was found to be composed of eDNA, as DNAse 1 treatment decreased the biofilm. Watters et al. used streptozotocin to induce diabetes in healthy mice. They infected a surgical excision wound with $P$. aeruginosa PAO1 and investigated the effect of the infection on the murine model wound healing [157]. It was observed that wound healing for diabetic mice was slow relative to healthy mice. Analysis of tissue extract of wound from diabetic mice revealed aggregates of $P$. aeruginosa. The biofilm did not respond to gentamicin treatment as 
was expected. $P$. aeruginosa biofilms are also known to cause CF. Bjarnsholt et al. showed using various imaging techniques that $P$. aeruginosa biofilms were localized in the conductive zone of CF-infected lungs as opposed to the respiratory zone, which is enriched with polymorphonuclear leukocytes (Figure 14) [158]. In the conductive zone, the study suggested that the mucoid biofilms formed by the bacteria in the mucus are protected from antibiotics and host defense.

In an earlier study, Dalton et al. seeded multispecies biofilms from an in vitro culture into the wounds of mice to generate a polymicrobial wound infection [152]. This study also observed an impaired wound healing of wounded mice infected with the multispecies biofilm, and an increased tolerance to antimicrobial treatment. The in vitro-to-in vivo multispecies biofilm was made up of $S$. aureus, P. aeruginosa, E. faecalis and Finegoldia magna. It was observed within $48 \mathrm{~h}$ postup that $P$. aeruginosa took over the infection and was typically present at the leading edge of the infection.

The response of the innate immunity system to biofilm infection has been investigated. $S$. aureus biofilms were established on surgically implanted catheters in a mouse model (Figure 15) [7]. The study observed that the biofilms evaded TLR2 and TLR9 which are bacterial recognition receptors used by macrophages. Host inflammatory responses such as TNF- $\alpha$, IL-1 $\beta$ and several others were found to be attenuated. The levels of iNOS, responsible for synthesizing reactive nitrogen intermediates which have microbicidal activities, were observed to be significantly reduced. A corresponding increase in arginase-1 expression levels was observed. In fact, the overall response of the innate immunity was observed to be altered; a plausible explanation for the persistence of biofilms in vivo.

\section{Conclusion \& future perspective}

A major setback in the treatment of biofilm-related infections is the ineffectiveness of existing antibiotics due to the protective layers built by cells in the biofilm. There is therefore limited antibiotic penetration, so the community of sedentary cells persists even in the presence of antibiotics effective against their motile counterparts. The dispersion of matured biofilms may primarily require the disruption of the EPS matrix. Components of the EPS matrix such as alginate, Pel and Psl in P. aeruginosa biofilms could, therefore, be vital targets in the disruption of biofilm structure. With cells exposed, the drug compound may then exhibit bactericidal activity or act by dispersing the cells. On the other hand, the formation of new biofilms could be inhibited by preventing initial processes like attachment of cells to surfaces. This would be crucial in the development of medical and dental implants as they are easily colonized by biofilm-forming pathogenic bacteria. Nevertheless, the gap between observations made from an in vitro model and an in vivo model continues to be problematic. Choice of animal model, depending on how closely related the model is to humans, would be a critical parameter in the successful development of any antibiofilm drug.

\section{Open Access}

This work is licensed under the Creative Commons AttributionNonCommercial 3.0 Unported License. To view a copy of this license, visit http://creativecommons.org/licenses/by-nc-nd/3.0/

\section{Financial \& competing interests disclosure}

We are grateful to NSF (CBET 1264509) and Camille Dreyfus Foundation (Teacher-Scholar fellowship to HOS) for funding. $Y$ Zheng is supported by Kraybill biochemistry fellowship. The

\section{Executive summary}

\section{Background}

- Biofilms are defined as aggregated microorganism communities attached to surfaces and embedded in a selfproduced matrix which is composed of extracellular polysaccharide, DNA and proteins.

- There are three steps in biofilm formation: attachment, maturation and dispersion.

- The biofilm structure provides the bacteria with the ability to tolerate harsh environmental conditions, resistance to antibiotics and host immune systems, and provides an optimal environment for extracellular DNA (plasmid) exchange.

- Various human diseases are related to biofilm. Biofilms play an important role in dental diseases.

Signaling in biofilm formation

- Bacteria synchronize their gene expression by producing and responding to autoinducers. Quorum sensing regulates bioflm formation in several bacterial species.

- c-di-GMP is a second messenger that modulates a variety of bacterial growth phenotypes including biofilm formation.

- sRNAs are also biofilm regulators

Biofilms in vivo

- The microenvironment in vivo is different from that in vitro. It is important to investigate biofilms inhibition in vivo in animal models. 
authors have no other relevant affiliations or financial involvement with any organization or entity with a financial interest in or financial conflict with the subject matter or materials

\section{References}

1 Henrici AT. Studies of freshwater bacteria: I. A direct microscopic technique. J. Bacteriol. 25(3), 277-287 (1933).

2 Heukelekian H, Heller A. Relation between food concentration and surface for bacterial growth. J. Bacteriol. 40 (4), 547-558 (1940).

3 Hoiby N, Flensborg E, Beck B, Friis B, Jacobsen S, Jacobsen L. Pseudomonas aeruginosa infection in cystic fibrosis. Diagnostic and prognostic significance of Pseudomonas aeruginosa precipitins determined by means of crossed immunoelectrophoresis. Scand. J. Respir. Dis. 58(2), 65-79 (1977).

4 Costerton JW, Geesey GG, Cheng KJ. How bacteria stick. Sci. Am. 238(1), 86-95 (1978).

5 Deligianni E, Pattison S, Berrar D et al. Pseudomonas aeruginosa cystic fibrosis isolates of similar RAPD genotype exhibit diversity in biofilm forming ability in vitro. $B M C$ Microbiol. 10, 38 (2010).

6 Ludecke C, Jandt KD, Siegismund D et al. Reproducible biofilm cultivation of chemostat-grown Escherichia coli and investigation of bacterial adhesion on biomaterials using a non-constant-depth film fermenter. PLoS One 9(1), e84837 (2014).

7 Thurlow LR, Hanke ML, Fritz T et al. Staphylococcus aureus biofilms prevent macrophage phagocytosis and attenuate inflammation in vivo. J. Immunol. 186(11), 6585-6596 (2011).

8 Pammi M, Liang R, Hicks JM, Barrish J, Versalovic J. Farnesol decreases biofilms of Staphylococcus epidermidis and exhibits synergy with nafcillin and vancomycin. Pediatr. Res. 70 (6), 578-583 (2011).

9 Annous BA, Fratamico PM, Smith JL. Scientific status summary. J. Food Sci. 74(1), R24-R37 (2009).

10 Metwalli KH, Khan SA, Krom BP, Jabra-Rizk MA. Streptococcus mutans Candida albicans and the human mouth: a sticky situation. PLoS Pathog. 9 (10), e1003616 (2013).

11 Flemming HC, Neu TR, Wozniak DJ. The EPS matrix: the "house of biofilm cells". J. Bacteriol. 189(22), 7945-7947 (2007).

12 Zhang X, Bishop PL, Kupferle MJ. Measurement of polysaccharides and proteins in biofilm extracellular polymers. Water Sci. Technol. 37 (45), 345-348 (1998).

13 Nwodo UU, Green E, Okoh AI. Bacterial exopolysaccharides: functionality and prospects. Int. J. Mol. Sci. 13(11), 14002-14015 (2012).

14 Dawson LF, Valiente E, Faulds-Pain A, Donahue EH, Wren BW. Characterisation of clostridium difficile biofilm formation, a role for Spo0A. PLoS One 7(12), e50527 (2012).

15 Bales PM, Renke EM, May SL, Shen Y, Nelson DC. Purification and characterization of biofilm-associated EPS exopolysaccharides from ESKAPE organisms and other pathogens. PLoS One 8(6), e67950 (2013). discussed in the manuscript apart from those disclosed. No writing assistance was utilized in the production of this manuscript.

16 Prigent-Combaret C, Vidal O, Dorel C, Lejeune P. Abiotic surface sensing and biofilm-dependent regulation of gene expression in Escherichia coli. J. Bacteriol. 181(19), 5993-6002 (1999).

17 Davies DG, Geesey GG. Regulation of the alginate biosynthesis gene algC in Pseudomonas aeruginosa during biofilm development in continuous culture. Appl. Environ. Microbiol. 61(3), 860-867 (1995).

18 Grant WD, Sutherland IW, Wilkinson JF. Exopolysaccharide colanic acid and its occurrence in the Enterobacteriaceae. J. Bacteriol. 100 (3), 1187-1193 (1969).

19 Stevenson G, Andrianopoulos K, Hobbs M, Reeves PR. Organization of the Escherichia coli K-12 gene cluster responsible for production of the extracellular polysaccharide colanic acid. J. Bacteriol. 178(16), 4885-4893 (1996).

20 Reid AN, Whitfield C. Functional analysis of conserved gene products involved in assembly of Escherichia coli capsules and exopolysaccharides: evidence for molecular recognition between Wza and Wzc for colanic acid biosynthesis. J. Bacteriol. 187(15), 5470-5481 (2005).

21 Danese PN, Pratt LA, Kolter R. Exopolysaccharide production is required for development of Escherichia coli K-12 biofilm architecture. J. Bacteriol. 182(12), 3593-3596 (2000).

22 Friedman L, Kolter R. Genes involved in matrix formation in Pseudomonas aeruginosa PA14 biofilms. Mol. Microbiol. 51(3), 675-690 (2004).

23 Friedman L, Kolter R. Two genetic loci produce distinct carbohydrate-rich structural components of the Pseudomonas aeruginosa biofilm matrix. J. Bacteriol. 186(14), 4457-4465 (2004).

24 Jackson KD, Starkey M, Kremer S, Parsek MR, Wozniak DJ. Identification of $p s l$, a locus encoding a potential exopolysaccharide that is essential for Pseudomonas aeruginosa PAO1 biofilm formation. J. Bacteriol. 186(14), 4466-4475 (2004).

25 May TB, Shinabarger D, Maharaj R et al. Alginate synthesis by Pseudomonas aeruginosa: a key pathogenic factor in chronic pulmonary infections of cystic fibrosis patients. Clin. Microbiol. Rev. 4(2), 191-206 (1991).

26 Hodges NA, Gordon CA. Protection of Pseudomonas aeruginosa against ciprofloxacin and beta-lactams by homologous alginate. Antimicrob. Agents Chemother. 35(11), 2450-2452 (1991).

27 Simpson JA, Smith SE, Dean RT. Alginate inhibition of the uptake of Pseudomonas aeruginosa by macrophages. J. Gen. Microbiol. 134(1), 29-36 (1988).

28 Ma L, Wang J, Wang S et al. Synthesis of multiple Pseudomonas aeruginosa biofilm matrix exopolysaccharides is post-transcriptionally regulated. Environ. Microbiol. 14(8), 1995- 2005 (2012).

29 Coyne MJ, Russell KS, Coyle CL, Goldberg JB. The Pseudomonas aeruginosa algC gene encodes 
phosphoglucomutase, required for the synthesis of a complete lipopolysaccharide core. J. Bacteriol. 176(12), 3500-3507 (1994).

30 Colvin KM, Irie Y, Tart CS et al. The Pel and Psl polysaccharides provide Pseudomonas aeruginosa structural redundancy within the biofilm matrix. Environ. Microbiol. 14(8), 1913-1928 (2012).

31 Franklin MJ, Nivens DE, Weadge JT, Howell PL. Biosynthesis of the Pseudomonas aeruginosa extracellular polysaccharides, alginate, Pel, and Psl. Front. Microbiol. 2, 167 (2011).

32 Gacesa P. Bacterial alginate biosynthesis - recent progress and future prospects. Microbiology 144 (5), 1133-1143 (1998).

33 Stokke BT, Draget KI, Smidsrød O, Yuguchi Y, Urakawa H, Kajiwara K. Small-angle x-ray scattering and rheological characterization of alginate Gels. 1. Ca-Alginate Gels. Macromolecules 33(5), 1853-1863 (2000).

34 Mack D, Fischer W, Krokotsch A et al. The intercellular adhesin involved in biofilm accumulation of Staphylococcus epidermidis is a linear beta-1,6-linked glucosaminoglycan: purification and structural analysis. J. Bacteriol. 178(1), 175-183 (1996).

35 Cue DR, Lei MG, Lee C. Genetic regulation of the intercellular adhesion locus in staphylococci. Front. Cell. Infect. Microbiol. 2, 38 (2012).

36 Stanley NR, Lazazzera BA. Defining the genetic differences between wild and domestic strains of Bacillus subtilis that affect poly- $\gamma$-DL-glutamic acid production and biofilm formation. Mol. Microbiol. 57(4), 1143-1158 (2005).

37 Branda SS, Chu F, Kearns DB, Losick R, Kolter R. A major protein component of the Bacillus subtilis biofilm matrix. Mol. Microbiol. 59 (4), 1229-1238 (2006).

38 Frølund B, Palmgren R, Keiding K, Nielsen PH. Extraction of extracellular polymers from activated sludge using a cation exchange resin. Water Res. 30(8), 1749-1758 (1996).

39 Lynch DJ, Fountain TL, Mazurkiewicz JE, Banas JA. Glucan-binding proteins are essential for shaping Streptococcus mutans biofilm architecture. FEMS Microbiol. Lett. 268(2), 158-165 (2007).

40 Dueholm MS, Søndergaard MT, Nilsson M et al. Expression of Fap amyloids in Pseudomonas aeruginosa, P. fuorescens, and $P$. putida results in aggregation and increased biofilm formation. Microbiologyopen 2(3), 365-382 (2013).

41 Romero D, Aguilar C, Losick R, Kolter R. Amyloid fibers provide structural integrity to Bacillus subtilis biofilms. Proc. Natl. Acad. Sci. USA 107(5), 2230-2234 (2010).

42 Cucarella C, Solano C, Valle J, Amorena B, Lasa I, Penadés JR. Bap, a Staphylococcus aureus surface protein involved in biofilm formation. J. Bacteriol. 183(9), 2888-2896 (2001).

43 Toledo-Arana A, Valle J, Solano C et al. The enterococcal surface protein, Esp, is involved in Enterococcus faecalis biofilm formation. Appl. Environ. Microbiol. 67(10), 4538-4545 (2001).

44 Lasa I, Penadés JR. Bap: a family of surface proteins involved in biofilm formation. Res. Microbiol. 157(2), 99-107 (2006).
45 Mora P, Rosconi F, Franco Fraguas L, Castro-Sowinski $S$. Azospirillum brasilense $\mathrm{Sp} 7$ produces an outer-membrane lectin that specifically binds to surface-exposed extracellular polysaccharide produced by the bacterium. Arch. Microbiol. 189(5), 519-524 (2008).

46 Diggle SP, Stacey RE, Dodd C, Cámara M, Williams P, Winzer K. The galactophilic lectin, LecA, contributes to biofilm development in Pseudomonas aeruginosa. Environ. Microbiol. 8(6), 1095-1104 (2006).

47 Tielker D, Hacker S, Loris R et al. Pseudomonas aeruginosa lectin LecB is located in the outer membrane and is involved in biofilm formation. Microbiology 151(5), 1313-1323 (2005).

48 Zhang X, Bishop PL. Biodegradability of biofilm extracellular polymeric substances. Chemosphere 50(1), 63-69 (2003).

49 Kaplan JB, Velliyagounder K, Ragunath C et al. Genes involved in the synthesis and degradation of matrix polysaccharide in Actinobacillus actinomycetemcomitans and Actinobacillus pleuropneumoniae biofilms. J. Bacteriol. 186(24), 8213-8220 (2004).

50 Whitchurch CB, Tolker-Nielsen T, Ragas PC, Mattick JS. Extracellular DNA required for bacterial biofilm formation. Science 295(5559), 1487 (2002).

51 Hamilton HL, Domínguez NM, Schwartz KJ, Hackett KT, Dillard JP. Neisseria gonorrhoeae secretes chromosomal DNA via a novel type IV secretion system. Mol. Microbiol. 55(6), 1704-1721 (2005).

52 Das T, Sharma PK, Busscher HJ, van der Mei HC, Krom BP. Role of extracellular DNA in initial bacterial adhesion and surface aggregation. Appl. Environ. Microbiol. 76(10), 3405-3408 (2010).

53 Gloag ES, Turnbull L, Huang A et al. Self-organization of bacterial biofilms is facilitated by extracellular DNA. Proc. Natl. Acad. Sci. USA 110 (28), 11541-11546 (2013).

54 Lewenza S. Extracellular DNA-induced antimicrobial peptide resistance mechanisms in Pseudomonas aeruginosa. Front. Microbiol. 4, 21 (2013).

55 Mulcahy H, Charron-Mazenod L, Lewenza S. Extracellular DNA chelates cations and induces antibiotic resistance in Pseudomonas aeruginosa biofilms. PLoS Pathog. 4(11), e1000213 (2008).

56 Johnson L, Horsman SR, Charron-Mazenod L et al. Extracellular DNA-induced antimicrobial peptide resistance in Salmonella enterica serovar Typhimurium. BMC Microbiol. 13, 115 (2013).

57 Doroshenko N, Tseng BS, Howlin RP et al. Extracellular DNA impedes the transport of vancomycin in Staphylococcus epidermidis biofilms pre-exposed to sub-inhibitory concentrations of vancomycin. Antimicrob. Agents Chemother.58(12), 7273-7282 (2014).

58 Otto M. Staphylococcus epidermidis Pathogenesis. Methods Mol. Biol. 1106, 17-31 (2014).

59 Barnes AMT, Ballering KS, Leibman RS, Wells CL, Dunny GM. Enterococcus faecalis produces abundant extracellular structures containing DNA in the absence of cell lysis during early biofilm formation. MBio. 3(4), e00193-12 (2012). 
60 Jefferson KK. What drives bacteria to produce a biofilm? FEMS Microbiol. Lett. 236(2), 163-173 (2004).

61 Rasmussen TB, Givskov M. Quorum-sensing inhibitors as anti-pathogenic drugs. Int. J. Med. Microbiol. 296(23), 149-161 (2006).

62 Hausner M, Wuertz S. High rates of conjugation in bacterial biofilms as determined by quantitative in situ analysis. Appl. Environ. Microbiol. 65(8), 3710-3713 (1999).

63 Palmer J, Flint S, Brooks J. Bacterial cell attachment, the beginning of a biofilm. J. Ind. Microbiol. Biotechnol. 34(9), 577-588 (2007)

64 Renner LD, Weibel DB. Physicochemical regulation of biofilm formation. MRS Bull. 36(5), 347-355 (2011).

65 Sutherland I. Biofilm exopolysaccharides: a strong and sticky framework. Microbiology 147(1), 3-9 (2001).

66 O’Toole GA, Kolter R. Flagellar and twitching motility are necessary for Pseudomonas aeruginosa biofilm development. Mol. Microbiol. 30 (2), 295-304 (1998).

67 Otto M. Staphylococcal biofilms. Curr. Top. Microbiol. Immunol. 207-228 (2008).

68 Heilmann C, Hussain M, Peters G, Götz F. Evidence for autolysin-mediated primary attachment of Staphylococcus epidermidis to a polystyrene surface. Mol. Microbiol. 24(5), 1013-1024 (1997).

69 Davies DG, Chakrabarty AM, Geesey GG. Exopolysaccharide production in biofilms: substratum activation of alginate gene expression by Pseudomonas aeruginosa. Appl. Environ. Microbiol. 59(4), 1181-1186 (1993).

70 Garrett ES, Perlegas D, Wozniak DJ. Negative control of flagellum synthesis in Pseudomonas aeruginosa is modulated by the alternative sigma factor $\mathrm{AlgT}(\mathrm{AlgU})$. J. Bacteriol. 181(23), 7401-7404 (1999).

71 Hall MR, McGillicuddy E, Kaplan LJ. Biofilm: basic principles, pathophysiology, and implications for clinicians. Surg. Infect. (Larchmt.) 15(1), 1-7 (2014).

72 Fux CA, Costerton JW, Stewart PS, Stoodley P. Survival strategies of infectious biofilms. Trends Microbiol. 13(1), 34-40 (2005).

73 Davies D. Understanding biofilm resistance to antibacterial agents. Nat. Rev. Drug Discov. 2(2), 114-122 (2003).

74 Lyczak JB, Cannon CL, Pier GB. Lung infections associated with cystic fibrosis. Clin. Microbiol. Rev. 15(2), 194-222 (2002).

75 Pedersen SS, Koch C, Høiby N, Rosendal K. An epidemic spread of multiresistant Pseudomonas aeruginosa in a cystic fibrosis centre. J. Antimicrob. Chemother. 17(4), 505-516 (1986).

76 Jones AM, Govan JR, Doherty CJ et al. Spread of a multiresistant strain of Pseudomonas aeruginosa in an adult cystic fibrosis clinic. Lancet 358(9281), 557-558 (2001).

77 Römling U, Fiedler B, Bosshammer J et al. Epidemiology of chronic Pseudomonas aeruginosa infections in cystic fibrosis. J. Infect. Dis. 170(6), 1616-1621 (1994).
78 Costerton JW, Stewart PS, Greenberg EP. Bacterial biofilms: a common cause of persistent infections. Science 284(5418), 1318-1322 (1999).

79 Moreau-Marquis S, Stanton BA, O'Toole GA. Pseudomonas aeruginosa biofilm formation in the cystic fibrosis airway. Pulm. Pharmacol. Ther. 21(4), 595-599 (2008).

80 Pedersen SS, Høiby N, Espersen F, Koch C. Role of alginate in infection with mucoid Pseudomonas aeruginosa in cystic fibrosis. Thorax 47(1), 6-13 (1992).

81 Hojo K, Nagaoka S, Ohshima T, Maeda N. Bacterial interactions in dental biofilm development. J. Dent. Res. 88(11), 982-990 (2009).

82 Marsh PD. Dental plaque as a microbial biofilm. Caries Res. 38(3), 204-211 (2004).

83 Marsh PD. Dental plaque as a biofilm and a microbial community - implications for health and disease. BMC Oral Health 6(Suppl 1), 14 (2006).

84 Zaura E, Keijser B, Huse S, Crielaard W. Defining the healthy "core microbiome" of oral microbial communities. BMC Microbiol. 9(1), 259 (2009).

85 Li J, Helmerhorst EJ, Leone CW et al. Identification of early microbial colonizers in human dental biofilm. J. Appl. Microbiol. 97(6), 1311-1318 (2004).

86 Marquis RE. Oxygen metabolism, oxidative stress and acid-base physiology of dental plaque biofilms. J. Ind. Microbiol. 15(3), 198-207 (1995).

87 Sbordone L, Bortolaia C. Oral microbial biofilms and plaque-related diseases: microbial communities and their role in the shift from oral health to disease. Clin. Oral Investig. 7(4), 181-188 (2003).

88 Dige I, Nilsson H, Kilian M, Nyvad B. In situ identification of streptococci and other bacteria in initial dental biofilm by confocal laser scanning microscopy and fluorescence in situ hybridization. Eur. J. Oral Sci. 115(6), 459-467 (2007).

89 Dige I, Raarup MK, Nyengaard JR, Kilian M, Nyvad B. Actinomyces naeslundii in initial dental biofilm formation. Microbiology 155(7), 2116-2126 (2009).

90 Kolenbrander PE, Palmer RJ Jr, Periasamy S, Jakubovics NS. Oral multispecies biofilm development and the key role of cell-cell distance. Nat. Rev. Micro. 8(7), 471-480 (2010).

91 Hardie KR, Heurlier K. Establishing bacterial communities by 'word of mouth': LuxS and autoinducer 2 in biofilm development. Nat. Rev. Micro. 6(8), 635-643 (2008).

92 Bassler BL, Greenberg EP, Stevens AM. Cross-species induction of luminescence in the quorum-sensing bacterium Vibrio harveyi. J. Bacteriol. 179(12), 4043-4045 (1997).

93 James GA, Swogger E, Wolcott R et al. Biofilms in chronic wounds. Wound Repair Regen. 16(1), 37-44 (2008).

94 Tenke P, Kovacs B, Jäckel M, Nagy E. The role of biofilm infection in urology. World J. Urol. 24(1), 13-20 (2006).

95 Jacobsen SM, Stickler DJ, Mobley HL, Shirtliff ME. Complicated catheter-associated urinary tract infections due to Escherichia coli and Proteus mirabilis. Clin. Microbiol. Rev. 21(1), 26-59 (2008). 
96 Matthews PC, Berendt AR, McNally MA, Byren I. Diagnosis and management of prosthetic joint infection. BMJ 338, b1773 (2009).

97 Trampuz A, Zimmerli W. Prosthetic joint infections: update in diagnosis and treatment. Swiss Med. Wkly. 135(1718), 243-251 (2005).

98 Khardori N, Yassien M. Biofilms in device-related infections. J. Ind. Microbiol. 15(3), 141-147 (1995).

99 Costerton JW, Lewandowski Z, Caldwell DE, Korber DR, Lappin-Scott HM. Microbial Biofilms. Annu. Rev. Microbiol. 49(1), 711-745 (1995).

100 Nickel JC, Ruseska I, Wright JB, Costerton JW. Tobramycin resistance of Pseudomonas aeruginosa cells growing as a biofilm on urinary catheter material. Antimicrob. Agents Chemother. 27(4), 619-624 (1985).

101 Luppens SB, Reij MW, van der Heijden RW, Rombouts FM, Abee T. Development of a standard test to assess the resistance of Staphylococcus aureus biofilm cells to disinfectants. Appl. Environ. Microbiol. 68(9), 4194-4200 (2002).

102 Suci PA, Mittelman MW, Yu FP, Geesey GG. Investigation of ciprofloxacin penetration into Pseudomonas aeruginosa biofilms. Antimicrob. Agents Chemother. 38(9), 2125-2133 (1994).

103 Anderl JN, Franklin MJ, Stewart PS. Role of antibiotic penetration limitation in Klebsiella pneumoniae biofilm resistance to ampicillin and ciprofloxacin. Antimicrob. Agents Chemother. 44(7), 1818-1824 (2000).

104 Savage VJ, Chopra I, O’Neill AJ. Staphylococcus aureus biofilms promote horizontal transfer of antibiotic resistance. Antimicrob. Agents Chemother. 57(4), 1968-1970 (2013).

105 Ashby MJ, Neale JE, Knott SJ, Critchley IA. Effect of antibiotics on non-growing planktonic cells and biofilms of Escherichia coli. J. Antimicrob. Chemother. 33(3), 443-452 (1994).

106 Lewis K. Persister cells, dormancy and infectious disease. Nat. Rev. Microbiol. 5(1), 48-56 (2007).

107 Keren I, Shah D, Spoering A, Kaldalu N, Lewis K. Specialized persister cells and the mechanism of multidrug tolerance in Escherichia coli. J. Bacteriol. 186(24), 8172-8180 (2004).

108 Zhang L, Mah TF. Involvement of a novel efflux system in biofilm-specific resistance to antibiotics. $J$. Bacteriol. 190 (13), 4447-4452 (2008).

109 Leid JG, Willson CJ, Shirtliff ME, Hassett DJ, Parsek MR, Jeffers AK. The exopolysaccharide alginate protects Pseudomonas aeruginosa biofilm bacteria from IFNgamma-mediated macrophage killing. J. Immunol. 175(11), 7512-7518 (2005).

110 Lyon GJ, Muir TW. Chemical signaling among bacteria and its inhibition. Chem. Biol. 10(11), 1007-1021 (2003).

111 West SA, Winzer K, Gardner A, Diggle SP. Quorum sensing and the confusion about diffusion. Trends Microbiol. 20(12), 586-594 (2012).

112 Camilli A, Bassler BL. Bacterial small-molecule signaling pathways. Science 311(5764), 1113-1116 (2006).
113 Rezzonico F, Duffy B. Lack of genomic evidence of AI-2 receptors suggests a non-quorum sensing role for lux $\mathrm{S}$ in most bacteria. BMC Microbiol. 8, 154 (2008).

114 Miller MB, Bassler BL. Quorum sensing in bacteria. Annu. Rev. Microbiol. 55(1), 165-199 (2001).

115 Romeo T, Irie Y, Parsek MR. Quorum sensing and microbial biofilms. Curr. Top. Microbiol. Immunol. 67-84 (2008).

116 Allesen-Holm M, Barken KB, Yang L et al. A characterization of DNA release in Pseudomonas aeruginosa cultures and biofilms. Mol. Microbiol. 59(4), 1114-1128 (2006).

117 Sakuragi Y, Kolter R. Quorum-sensing regulation of the biofilm matrix genes (pel) of Pseudomonas aeruginosa. J. Bacteriol. 189(14), 5383-5386 (2007).

118 Boles BR, Horswill AR. Agr-mediated dispersal of Staphylococcus aureus biofilms. PLoS Pathog. 4(4), e1000052 (2008).

119 Novick RP, Geisinger E. Quorum sensing in staphylococci. Annu. Rev. Genet. 42, 541-564 (2008).

120 López D, Fischbach MA, Chu F, Losick R, Kolter R. Structurally diverse natural products that cause potassium leakage trigger multicellularity in Bacillus subtilis. Proc. Natl. Acad. Sci. USA 106(1), 280-285 (2009).

121 Weinhouse H, Sapir S, Amikam D et al. c-di-GMP-binding protein, a new factor regulating cellulose synthesis in Acetobacter xylinum. FEBS Lett. 416(2), 207-211 ( 1997).

122 Ross $\mathrm{P}$, Mayer R, Weinhouse $\mathrm{H}$ et al. The cyclic diguanylic acid regulatory system of cellulose synthesis in Acetobacter xylinum chemical synthesis and biological activity of cyclic nucleotide dimer, trimer, and phosphothioate derivatives. J. Biol. Chem. 265(31), 18933-18943 (1990).

123 Kalia D, Merey G, Nakayama S et al. Nucleotide, c-di-GMP, c-di-AMP, cGMP, cAMP, (p)ppGpp signaling in bacteria and implications in pathogenesis. Chem. Soc. Rev. 42(1), 305-341 (2013).

124 Ross P, Weinhouse H, Aloni Y et al. Regulation of cellulose synthesis in Acetobacter xylinum by cyclic diguanylic acid. Nature 325(6101), 279-281 (1987).

125 Ryjenkov DA, Tarutina M, Moskvin OV, Gomelsky M. Cyclic diguanylate is a ubiquitous signaling molecule in bacteria: insights into biochemistry of the GGDEF protein domain. J. Bacteriol. 187(5), 1792-1798 (2005).

126 Paul R, Weiser S, Amiot NC et al. Cell cycle-dependent dynamic localization of a bacterial response regulator with a novel di-guanylate cyclase output domain. Genes Dev. 18(6), 715-727 (2004).

127 Tischler AD, Camilli A. Cyclic diguanylate regulates Vibrio cholerae virulence gene expression. Infect. Immun. 73(9), 5873-5882 (2005).

128 Boyd CD, O'Toole GA. Second messenger regulation of biofilm formation: breakthroughs in understanding c-di-GMP effector systems. Annu. Rev. Cell Dev. Biol. 28, 439-462 (2012).

129 Newell PD, Monds RD, O'Toole GA. LapD is a bis- $\left(3^{\prime}, 5^{\prime}\right)-$ cyclic dimeric GMP-binding protein that regulates surface attachment by Pseudomonas fluorescens Pf0-1. Proc. Natl Acad. Sci. USA 106(9), 3461-3466 (2009). 
130 Newell PD, Boyd CD, Sondermann H, O’Toole GA. A c-di-GMP effector system controls cell adhesion by insideout signaling and surface protein cleavage. PLoS Biol. 9(2), e1000587 (2011)

131 Monds RD, Newell PD, Gross RH, O’Toole GA. Phosphate-dependent modulation of c-di-GMP levels regulates Pseudomonas fluorescens $\mathrm{Pf} 0-1$ biofilm formation by controlling secretion of the adhesin LapA. Mol. Microbiol. 63(3), 656-679 (2007).

132 Ryjenkov DA, Simm R, Römling U, Gomelsky M. The PilZ domain is a receptor for the second messenger c-di-GMP: the PilZ domain protein YcgR controls motility in enterobacteria. J. Biol. Chem. 281(41), 30310-30314 (2006).

133 Boehm A, Kaiser M, Li H et al. Second messenger-mediated adjustment of bacterial swimming velocity. Cell 141(1), 107-116 (2010).

134 Paul K, Nieto V, Carlquist WC, Blair DF, Harshey RM. The c-di-GMP binding protein YcgR controls flagellar motor direction and speed to affect chemotaxis by a "backstop brake" mechanism. Mol. Cell 38(1), 128-139 (2010).

135 Martinez-Wilson HF, Tamayo R, Tischler AD, Lazinski DW, Camilli A. The Vibrio cholerae hybrid sensor kinase $\mathrm{VieS}$ contributes to motility and biofilm regulation by altering the cyclic diguanylate level. J. Bacteriol. 190(19), 6439-6447 (2008).

136 Tamayo R, Tischler AD, Camilli A. The EAL Domain protein VieA is a cyclic diguanylate phosphodiesterase. J. Biol. Chem. 280 (39), 33324-33330 (2005).

137 Simm R, Morr M, Kader A, Nimtz M, Römling U. GGDEF and EAL domains inversely regulate cyclic diGMP levels and transition from sessility to motility. Mol. Microbiol. 53(4), 1123-1134 (2004).

138 Kirillina O, Fetherston JD, Bobrov AG, Abney J, Perry RD. HmsP, a putative phosphodiesterase, and $\mathrm{Hms} \mathrm{T}$, a putative diguanylate cyclase, control Hms-dependent biofilm formation in Yersinia pestis. Mol. Microbiol. 54(1), 75-88 (2004).

139 Wilksch JJ, Yang J, Clements A et al. MrkH, a novel c-di-GMP-dependent transcriptional activator, controls Klebsiella pneumoniae biofilm formation by regulating type 3 fimbriae expression. PLoS Pathog. 7(8), e1002204 (2011).

140 Carlson HK, Vance RE, Marletta MA. H-NOX regulation of c-di-GMP metabolism and biofilm formation in Legionella pneumophila. Mol. Microbiol. 77(4), 930-942 (2010).

141 Nakhamchik A, Wilde C, Rowe-Magnus DA. Cyclic-diGMP regulates extracellular polysaccharide production, biofilm formation, and rugose colony development by Vibrio vulnificus. Appl. Environ. Microbiol. 74(13), 4199-4209 (2008).

142 Romeo T, Gong M, Liu MY, Brun-Zinkernagel AM. Identification and molecular characterization of csrA, a pleiotropic gene from Escherichia coli that affects glycogen biosynthesis, gluconeogenesis, cell size, and surface properties. J. Bacteriol. 175(15), 4744-4755 (1993).

143 Liu MY, Gui G, Wei B et al. The RNA molecule CsrB binds to the global regulatory protein CsrA and antagonizes its activity in Escherichia coli. J. Biol. Chem. 272(28), 17502 17510 (1997).
144 Jackson DW, Suzuki K, Oakford L, Simecka JW, Hart ME, Romeo T. Biofilm formation and dispersal under the influence of the global regulator CsrA of Escherichia coli.J. Bacteriol. 184(1), 290-301 (2002).

145 Ventre I, Goodman AL, Vallet-Gely I et al. Multiple sensors control reciprocal expression of Pseudomonas aeruginosa regulatory RNA and virulence genes. Proc. Natl Acad. Sci. USA 103(1), 171-176 (2006).

146 Kay E, Humair B, Dénervaud V et al. Two GacA-dependent small RNAs modulate the quorum-sensing response in Pseudomonas aeruginosa. J. Bacteriol. 188(16), 6026-6033 (2006).

147 Jimenez PN, Koch G, Thompson JA, Xavier KB, Cool RH, Quax WJ. The multiple signaling systems regulating virulence in Pseudomonas aeruginosa. Microbiol. Mol. Biol. Rev. 76(1), 46-65 (2012).

148 Babitzke P, Romeo T. CsrB sRNA family: sequestration of RNA-binding regulatory proteins. Curr. Opin. Microbiol. 10(2), 156-163 (2007).

149 Ogasawara H, Yamamoto K, Ishihama A. Role of the biofilm master regulator $\mathrm{CsgD}$ in cross-regulation between biofilm formation and flagellar synthesis. J. Bacteriol. 193(10), 2587-2597 (2011).

150 Mika F, Hengge R. Small RNAs in the control of RpoS, CsgD, and biofilm architecture of Escherichia coli. RNA Biol. 11(5), 494-507 (2014).

151 Chambers JR, Sauer K. Small RNAs and their role in biofilm formation. Trends Microbiol. 21(1), 39-49 (2013).

152 Dalton T, Dowd SE, Wolcott RD et al. An in vivo polymicrobial biofilm wound infection model to study interspecies interactions. PLoS One 6(11), e27317 (2011).

153 Hoffmann N, Rasmussen TB, Jensen PØ et al. Novel mouse model of chronic Pseudomonas aeruginosa lung infection mimicking cystic fibrosis. Infect. Immun. 73(4), 2504-2514 (2005).

154 Buret A, Ward KH, Olson ME, Costerton JW. An in vivo model to study the pathobiology of infectious biofilms on biomaterial surfaces. J. Biomed. Mater. Res. 25(7), 865-874 (1991).

155 Chauhan A, Lebeaux D, Decante B et al. A rat model of central venous catheter to study establishment of long-term bacterial biofilm and related acute and chronic infections. PLoS One 7(5), e37281 (2012).

156 Cole SJ, Records AR, Orr MW, Linden SB, Lee VT. Catheter-associated urinary tract infection by Pseudomonas aeruginosa is mediated by exopolysaccharide independent biofilms. Infect. Immun. 82(5), 2048-2058 (2014).

157 Watters C, DeLeon K, Trivedi U et al. Pseudomonas aeruginosa biofilms perturb wound resolution and antibiotic tolerance in diabetic mice. Med. Microbiol. Immunol. 202(2), 131-141 (2013).

158 Bjarnsholt T, Jensen PØ, Fiandaca MJ et al. Pseudomonas aeruginosa biofilms in the respiratory tract of cystic fibrosis patients. Pediatr. Pulmonol. 44(6), 547-558 (2009). 